\title{
Ubiquitination and SUMOylation of Amyloid and Amyloid-like Proteins in Health and Disease
}

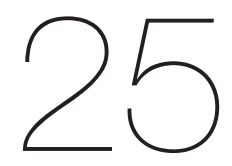

\author{
Lenzie Ford ${ }^{1,2,3}$, Luana Fioriti ${ }^{4,5}$, and Eric R. Kandel ${ }^{1,2,3,6 *}$
}

\author{
${ }^{1}$ Department of Neuroscience, Columbia University, New York, NY, USA. \\ ${ }^{2}$ Howard Hughes Medical Institute, Chevy Chase, MD, USA. \\ ${ }^{3}$ Mortimer B. Zuckerman Mind Brain Behavior Institute, Columbia University, New York, NY, \\ USA. \\ ${ }^{4}$ Istituto di Ricerche Farmacologiche Mario Negri, Istituto di Ricovero e Cura a Carattere \\ Scientifico, Milan, Italy. \\ ${ }^{5}$ Dulbecco Telethon Institute, Fondazione Telethon, Rome, Italy. \\ ${ }^{6}$ Kavli Institute for Brain Science, Columbia University, New York, NY, USA. \\ *Correspondence: erk5@columbia.edu
}

https://doi.org/10.21775/9781912530120.25

\begin{abstract}
Post-translational modifications (PTMs) play important roles in altering the structure and function of proteins. In this chapter, we focus on ubiquitination and SUMOylation of amyloidogenic proteins. We discuss the functional contributions of PTMs on proteins involved in amyloid-related diseases as well as the aberrant PTM signatures of the disease agents. In addition, we extend our discussion to the nascent field of functional amyloids, a subclass of amyloids that perform physiological functions. Here, we present examples from mammals and yeast to gain insight into physiological regulation of amyloid-like proteins.
\end{abstract}

\section{Introduction}

\section{Post-translational modifications}

Post-translational modifications (PTMs) involve the covalent conjugation of a chemical moiety to a target protein. Depending on the moiety, these modifications can be stable or highly dynamic. PTMs represent a global regulatory mechanism that is involved in virtually all aspects of cell biology (Mann and Jensen, 2003), including subcellular localization and trafficking, molecular interactions, state of activity, and molecular stability and degradation. There are many types of PTMs, such as phosphorylation, acetylation, glycosylation, and methylation. This article focuses specifically on ubiquitination and SUMOylation.

\section{Ubiquitination}

Since the initial discovery of ubiquitin-mediated targeting of proteins for degradation (Hershko and Ciechanover, 1998), tens of thousands of ubiquitination sites have been identified on thousands of substrate proteins using proteomic techniques (Peng et al., 2003; Kim et al., 2011; Wagner et al., 2011). The ubiquitination process is complex, with over 1000 proteins regulating ubiquitination in human cells (Clague et al., 2015). The process is further complicated by a three-step enzymatic cascade (Fig. 25.1), which is necessary to covalently conjugate ubiquitin to its target protein. First, an E1 ubiquitin activating enzyme supplies the energy for the reaction (Shulman and Harper, 2009), followed 


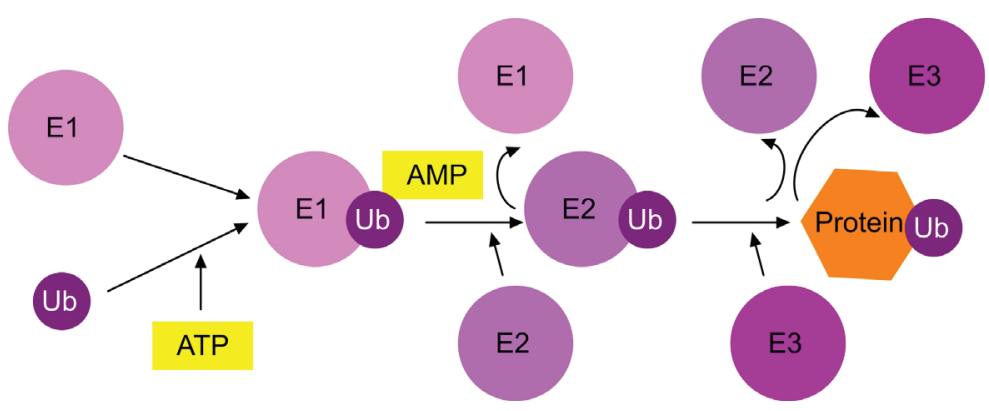

Figure 25.1 The ubiquitination cycle. Schematic of the ubiquitination enzymatic cascade. Ubiquitin (Ub) is activated in an energy-dependent manner by E1. Ubiquitin is then passed from E1 to E2. E3 interacts with the substrate (orange protein) to be ubiquitinated. Ultimately, it is E3 which conjugates ubiquitin to the substrate.

by an E2 conjugating enzyme (Ye and Rape, 2009), and then an E3 ubiquitin ligating enzyme (Deshaies et al., 2009; Rotin and Kumar, 2009; Smit and Sixma, 2014). Often, ubiquitin is conjugated via the C-terminal glycine to a lysine residue on the target protein (Pickart, 2001). Ubiquitination can also occur through conjugation to the $\mathrm{N}$-terminus of the target protein, although this covalent attachment is less common (Pickart, 2001). Deubiquitinases (DUBs) specialize in the removal of ubiquitin from substrate proteins (Komander et al., 2009; Clague et al., 2013).

Ubiquitin is a 76 amino acid protein and contains various sites for post-translational modification. Importantly, ubiquitin contains seven lysine resides which can be modified and eleven potential phosphorylation sites (Swatek and Komander, 2016). This allows for the formation of polyubiquitin chains and greatly increases complexity. On these identified residues, ubiquitin can be modified by ubiquitin and ubiquitin-like groups, acetyl-groups, and phospho-groups. These ubiquitin-like groups include SUMO (small ubiquitin-like modifier), NEDD8 (neural precursor cell expressed, developmentally down-regulated 8) (Kamitani et al., 1997), ISG 15 (interferon inducible gene 15) (Kessler et al., 1988), and ATG 8 (autophagic ubiquitin-like protein) (Ichimura et al., 2000).

The residue ubiquitinated and extent of ubiquitination, i.e. polyubiquitination versus monoubiquitination and the formation of ubiquitin branches, are critical for the destiny of the substrate protein. The majority of ubiquitination occurs via lysine 48 ubiquitin chain linkage and this targets the substrate to degradation, via the ubiquitin proteasome system (UPS) (Hershko and Ciechanover, 1998). Another prominent degradation signal is triggered by lysine 11 polyubiquitination (Finley, 2009). The second most prevalent ubiquitin modification occurs via lysine 63 linkage and is involved in various non-degradative roles (Chen and Sun, 2009).

Although more than $50 \%$ of ubiquitinated proteins are destined for proteasomal degradation, substrates can undergo other fates involved in protein activity and cellular localization (Seet et al., 2006) by inhibiting protein-protein interactions through steric hinderance. Specifically, polyubiquitin chains have functional roles in signalling, endocytosis, DNA repair, and macroautophagy (Kraft et al., 2010). Various other combinations create complex cellular signalling. For example, Met1-linked linear ubiquitin chains have been identified as being key positive regulators of NF- $\mathrm{BB}$ signalling (Swatek and Komander, 2016). Another example is Lys33 linked ubiquitin chains, which are involved in trafficking of the protein after exiting the Golgi (Yuan et al., 2014). Monoubiquitination can also influence various fates, depending on the residue modified. For example, monoubiquitination can play a role in sorting proteins into extracellular vesicles (Kunadt et al., 2005).

\section{SUMOylation}

As mentioned in the previous section, there exist various ubiquitin-like modifications, one of which is SUMO (small ubiquitin-like modifier). Although both ubiquitin and SUMO are similar in structure and require a three-enzyme cascade for substrate conjugation, ubiquitination and SUMOylation 
proteins have very distinct functions. Overall, ubiquitination is often generalized as a 'degradation' modification while SUMO is often generalized as either a 'solubility' or 'trafficking' modification. These generalization are, of course, an over-simplification of complex cellular signalling, but do indicate vastly distinct functions. A more in-depth discussion of SUMOylated protein function will follow. Another distinction between ubiquitination and SUMOylation of a substrate is in the E2 and E3 involved in their respective three-step enzymatic cascades, as discussed below.

Discovery of the yeast SUMO orthologue SMT3 paved the way for detailed functional studies of this highly soluble, globular protein and its role as a protein modifier (Meluh and Koshland, 1995). In mammals, SUMO1-5 exist as reversible protein modifiers which form isopeptide bonds with lysine residues of the target proteins (Mahajan et al., 1997) and SUMO family proteins are expressed ubiquitously across eukaryotic cell types (Melchior, 2000; Bohren et al., 2004; Guo et al., 2004). SUMOylation can lead to three nonmutually exclusive events: inhibition of interaction via steric hinderance, increase in interaction via recruitment, and change in conformation of the substrate (Wilkinson and Henley, 2010). This posttranslational modification is an essential cellular process and produces an embryonic lethal phenotype when knocked out in mice or mammalian cells (Hayashi et al., 2002; Nacerddine et al., 2005).

Similar to ubiquitination, SUMOylation occurs through a three-step enzymatic pathway. Specifically, for SUMOylation, an E1-activating enzyme (SAE1/SAE2) (Gong et al., 1999), an E2-conjugase (Ubc9), and an E3-ligase (Hay, 2005) are required (Fig. 25.2). SUMO is first activated by the heterodimer SAE1/SAE2 and then passed to the catalytic pocket of the E2 conjugase Ubc9. Ubc9 is the sole conjugating enzyme for all SUMOs and will not conjugate other proteins (Desterro et al., 1997). Through Ubc9-driven conjugation, SUMO forms an isopeptide bond with lysine. Lysines in the target protein are capable of being SUMOylated when part of a W-K-X-[D/E] consensus motif, in which $\mathrm{W}$ represents any large hydrophobic residue and $\mathrm{X}$ is any residue (Rodriguez et al., 2001, Sampson et al., 2001; Geiss-Friedlander, 2007). There

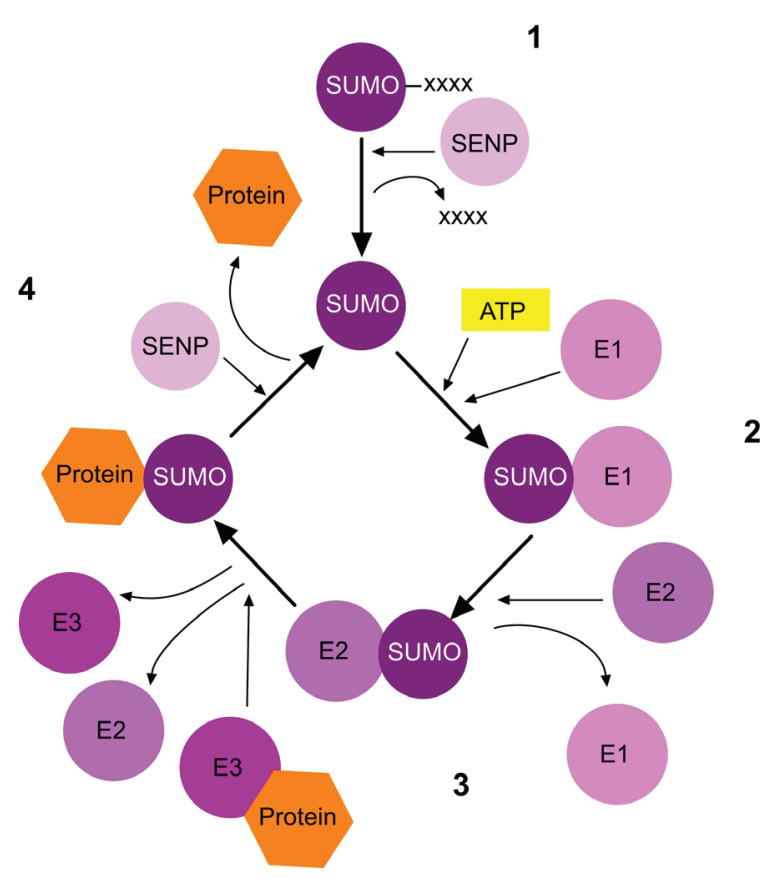

Figure 25.2 The SUMOylation cycle. Schematic of the SUMOylation pathway. SUMO protein is cleaved by SENP, followed by energy-dependent E1 binding. SUMO is then passed to E2. E3 conjugates the mature SUMO to the substrate (orange protein). The target protein can then be further polySUMOylated, or deSUMOylated via SENP. 
are three distinct families of E3 ligases involved in SUMOylation: SP-RING-finger-like, Ran binding protein 2 (RanBP2), and Polycomb protein 2 (Pc2) (Melchior et al., 2003). Sentrin-specific proteases (SENPs) and De-SUMOylating isopeptidase 1 and 2 (DeSI-1 and 2) are responsible for reversing SUMO conjugation (Potts and $\mathrm{Yu}, 2005$ ).

Of the five SUMO proteins, SUMO1, SUMO2, and SUMO3 are the most extensively studied. SUMO1 is a 101 amino acid protein, sharing only 47\% homology with SUMO2 and SUMO3. SUMO2 and SUMO3 are nearly identical and only vary in three amino acid residues. These three SUMOs are ubiquitously expressed. An important difference between SUMO1 and SUMO2/3 is the formation of polymeric chains. SUMO1 attaches as a single molecule only, whereas SUMO2/3 is capable of forming a chain due to a consensus SUMO motif in the N-terminus (Cheng et al., 2006). SUMO4 and SUMO5 expression is still under debate. Currently, SUMO4 mRNA expression has been found in lymph, kidney, and spleen (Guo et al., 2004) and does not appear to participate in conjugate formation, suggesting that it may be a pseudogene (Owerbach et al., 2005). SUMO5 has recently been discovered in primates, although expression is not detectable in the brain and remains a largely unexplored protein (Liang et al., 2016).

\section{Amyloidogenic proteins}

\section{Amyloids}

Amyloidogenic proteins, or amyloids, are characterized by (1) a propensity to fibrillize with a cross $\beta$ structure (Fig. 25.3A) and (2) an ability to bind the dye Congo Red, which produces green birefringence on illumination with polarized light (Serpell, 2000; Dobson, 2003). Many proteins display amyloid characteristics but lack a defined cross $\beta$ structure; for these proteins, we will refer to them as amyloid-like. Monomeric amyloids are soluble and often contain unstructured domains in aqueous solution (Baumketner et al., 2006), whereas fibrillization increases the insolubility of the protein and is accompanied by an increase in $\beta$-sheet formation, followed by various stages of self-assembly. The end product is an insoluble amyloid fibril that is proteinase $\mathrm{K}$ resistant (Dobson, 2003). These fibrils can further associate to form
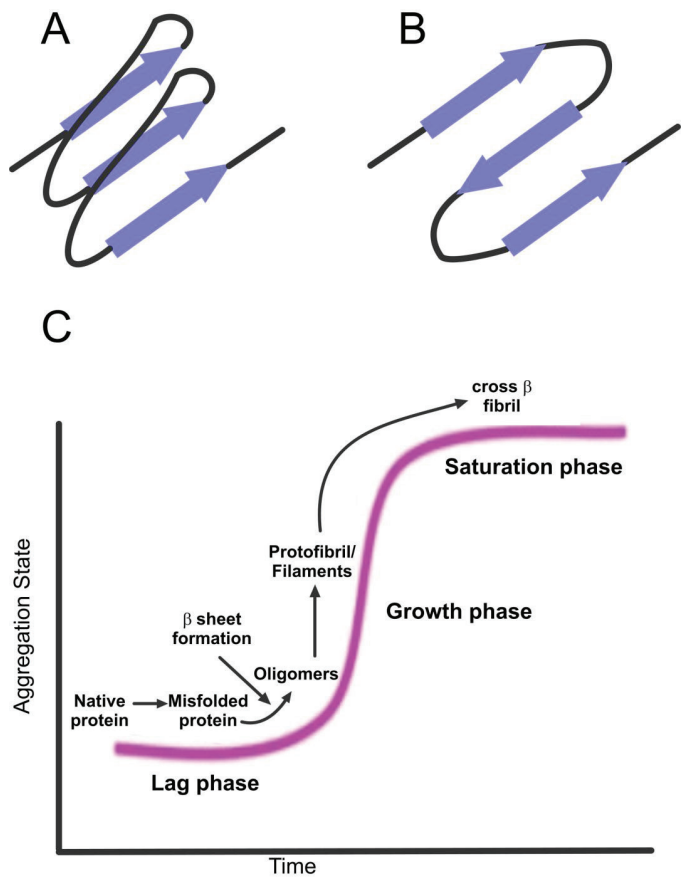

Figure 25.3 Amyloid fibrillization. (A) Cartoon examples of parallel $\beta$-sheets and $(B)$ antiparallel $\beta$-sheets. (C) Amyloid fibrillization plot showing the aggregation of a native protein into an amyloid fibril over time.

proteinaceous bodies, which are commonly found in neurodegenerative diseases. To initiate assembly from monomeric species, the fibrillization process requires a nucleation event. This event creates intermediate species, including oligomers, and then elongates before mature fibrils are fully formed (Fig. 25.3B). Side chains play an important role in associating several $\beta$-sheets between fibrillar components (Serpell, 2014). Other components influencing association include $\pi$ stacking between side chains, high net charge, exposure of aromatic side chains, exposed surface area, and dipole moments (Chiti and Dobson, 2006).

\section{Prions (proteinaceous infectious particles)}

Stanley Prusiner's seminal research on prion proteins and prion diseases led to the concept that an infectious disease could be caused by a proteinaceous agent, an idea that was initially met with great scepticism by the scientific community (Prusiner, 1982; Safar et al., 2005). However, several studies confirmed that prions were indeed infectious 


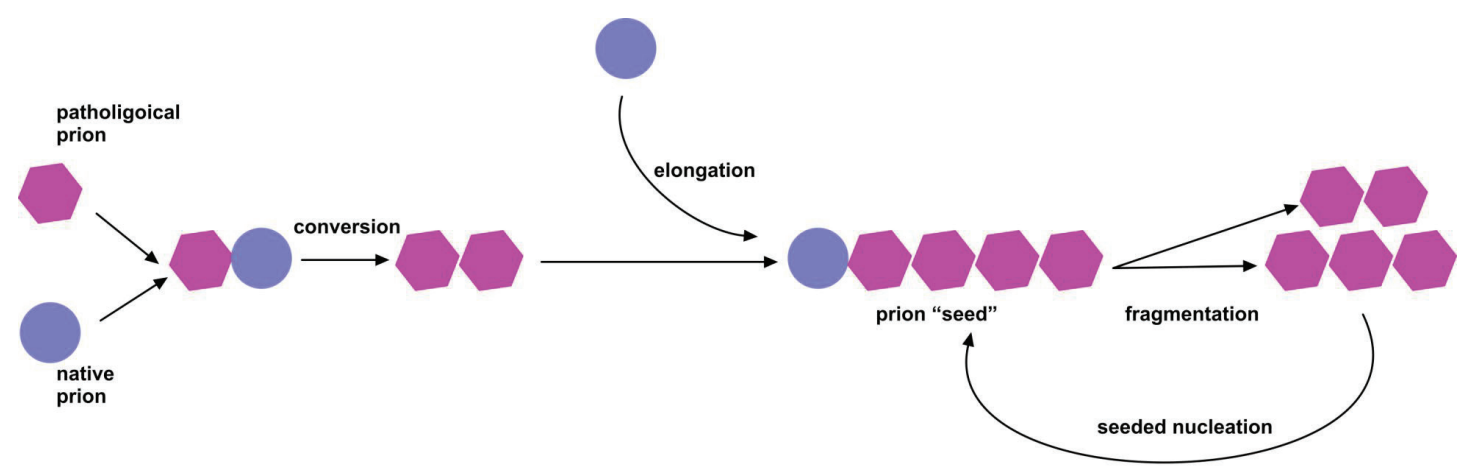

Figure 25.4 Prion conversion. Schematic of prion conversion pathway from functional (purple circle) to pathological (pink hexagon), including the critical steps of prion conversion, elongation, seeding, and fragmentation.

(Bolton et al., 1982; McKinley et al., 1983) and amyloid-like (Prusiner et al., 1983).

Prion diseases are characterized by the conversion of cellular prion protein $(\mathrm{PrP})$ to a pathogenic form (PrPsc) (Fig. 25.4). Whereas PrP exists as a soluble, cell-surface glycosyl phosphatidyl inositol-link glycoprotein, PrPsc is amyloidogenic and pathogenic. The pathogenicity of $\mathrm{PrPsc}$ is transmissible between organisms. Prion diseases in humans include kuru, Creutzfeldt-Jakob disease (CJD) (Gibbs et al., 1968), Gerstmann-StrausslerScheinker (GSS) disease, and fatal familial insomnia in humans. There are additional prion diseases found in non-human mammals including scrapie, transmissible mink encephalopathy, chronic wasting disease, and bovine spongiform encephalopathy (Aguzzi et al., 2007).

The protein characterization of 'prion' is very specific. For a protein to be considered an amyloid, it must convert to a cross- $\beta$ structure, and bind Congo Red with a green birefringence under polarized light (Serpell, 2000). These amyloid qualities are shared with prions. However, not all amyloids are prions. For an amyloid to also be a prion, it must have the additional characteristic of transmissibility (Prusiner, 2013). The definition of prion transmissibility remains a contested topic within the field. Are proteins prions only when transmissible across organisms, such as in PrPsc diseases? Are proteins prions when transmissible across cells? Organism transmissibility is certainly a prion trait; however, cellular transmissibility is a contended topic. For the purposes of this article, we will distinguish cellularly transmissible amyloidogenic proteins that lack clear evidence of organism transmissibility as 'prionoids' (Scheckel and Aguzzi, 2018).

Prionoids exist in many common neurological diseases, such as Alzheimer's disease and Parkinson's disease. Common prionoids include $\beta$-amyloid (Meyer-Luehmann et al., 2006; Eisele et al., 2010), tau (Clavaguera et al., 2009; Guo and Lee, 2011; Kfoury et al., 2012), a-synuclein (Braak et al., 1996, 2003), SOD1 (Münch et al., 2011), and Huntingtin (Ren et al., 2009). These prionoids are, of course, all amyloids. Many physiological proteins also have a propensity to adopt an amyloid-like structure and display transmissible heritability when expressed in yeast (Liebman and Chernoff, 2012). To distinguish proteins with the aforementioned characteristics, we will use the term prion-like (Frost and Diamond, 2012).

Amyloids fibrillize to form defined, specific structures. Often, amyloids and prions/prionoids/ prion-like proteins will be characterized as having 'aggregation' properties. Within the amyloid field, aggregation suggests a disordered assembly of proteins. Aggregation lacks control and does not specify self-association properties or specific structure of the proteins within the 'aggregates'. In this chapter, we use the terms 'aggregate' and 'fibrils' as the amyloid field uses them; i.e. fibrils are composed of self-assembled amyloids with cross $\beta$ structure, and aggregates are a disordered assembly and non-specific interaction of proteins.

\section{Inclusion bodies}

Deposits of aggregation-prone proteins are often termed inclusion bodies. A hallmark of many 
neurodegenerative diseases is the formation of amyloid inclusion bodies, although the contribution of amyloid inclusion bodies to neuronal death is still highly debated. Various hypotheses have been proposed to explain the role of inclusion bodies in neurodegenerative disease. For example, inclusion bodies may serve as a receptacle for misfolded and aggregating proteins. While some consider this a beneficial process whereby the cell captures toxic proteins, others consider the formation of inclusion bodies to provide a means of physical entrapment of functional proteins. Much of the data suggest that inclusion bodies indeed capture misfolded proteins that would otherwise prove cytotoxic (Wójcik et al., 1996; Johnston et al., 1998; GarcíaMata et al., 1999). Indeed, research suggests that ubiquitin-dependent proteasomal targeting of substrate proteins to inclusion bodies exists physiologically (Kawaguchi et al., 2003; Hao et al., 2013; Schipper-Krom et al., 2014), while restoration of the UPS in neurodegenerative disease correlates with increased inclusion body formation (Mitra et al., 2009; Ortega et al., 2010). Perhaps, inclusion bodies provide a mechanism that can contain toxic proteins that are so aggregated that the proteasome fails to efficiently degrade them (Ma and Lindquist, 2002).

Several of these inclusion bodies have been found to be SUMOylated in disease ( $\mathrm{Li}$ et al., 2003; Steffan et al., 2004; Riley et al., 2005; Fei et al., 2006; Krumova et al., 2011). There are multiple hypotheses on why aggregating amyloids and amyloid-like proteins may be SUMOylated. One hypothesis posits that SUMOylation is a general solubility enhancer that allows the cells to counteract aggregation. Another possibility is that SUMOylation provides steric hindrance to fibril formation and thus abrogates the extent of amyloid fibrillization. Finally, SUMO conjugation has been hypothesized to work as a chaperone and enhance the folding of the target protein. Indeed, SUMOylation also occurs on chaperone proteins, affecting their activity in protein quality control (Panse et al., 2004; Wohlschlegel et al., 2004; Denison et al., 2005). All hypotheses allow for the cellular regulation of toxic proteins with post-translational modifications.

Many inclusion bodies in neurodegenerative disease are also ubiquitinated (Dantuma and Bott, 2014). The UPS is an important component of neurodegenerative disease, considering its critical role as a protein homeostasis regulator. Importantly, it is the role of the UPS to degrade misfolded and aggregation-prone proteins in healthy systems. When an increase in aggregated protein overwhelms the system, a downstream decrease in normal homeostatic functioning of the UPS machinery occurs (Dantuma and Bott, 2014). This creates a dangerous hampering of the degradation machinery, as pathological amyloid formation continues to build and causes a feedback loop in which more amyloid will cause greater UPS impairment.

\section{Toxic amyloids}

\section{Synucleinopathies}

Synucleinopathies are a group of neurodegenerative diseases characterized by the aggregation of filamentous $\alpha$-synuclein into cytosolic inclusion bodies called Lewy bodies (Goedert, 2001). $\alpha$-synuclein is an intrinsically disordered protein, meaning that it has no defined secondary structure when unbound (Schweers et al., 1994), and it functions at the synapse in vesicle trafficking, plasticity, and inhibition of kinase signalling (Iwata et al., 2001; Chandra et al., 2004; Liu et al., 2004; Chandra et al., 2005; Liu et al., 2007). However, under disease conditions, $a$-synuclein undergoes a conformational change to a cross $\beta$-pleated sheet structure and continues along the path of amyloid fibrillization until ultimately depositing as a Lewy body (Fig. 25.5; Spillantini et al., 1997; Conway et al., 2000; Serpell et al., 2000; Ulmer et al., 2005; Guerrero-Ferriera et al., 2018; Rose et al., 2018).

$\alpha$-synuclein can be mono- and poly-ubiquitinated, where monoubiquitination promotes aggregation (Nonaka et al., 2005; Lee et al., 2008) and polyubiquitination at lysine 48 targets the protein to the proteasome (Lee et al., 2009). Indeed, increasing the pool of free ubiquitin decreases a-synuclein-driven neurodegeneration in a Drosophila disease model (Lee et al., 2009). An increased amount of free ubiquitin is thought to induce the polyubiquitination of $\alpha$-synuclein. This balance of the free ubiquitin pool, monoubiquitination of $\alpha$-synuclein, and the polyubiquitination of $\alpha$-synuclein is further complicated by toxic $\alpha$-synuclein-mediated inhibition of UPS function (Stefanis et al., 2001; Snyder et al., 2003; Chen 
A

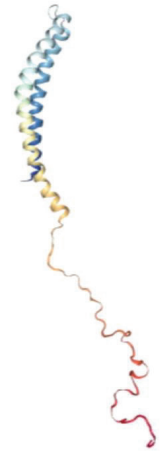

B

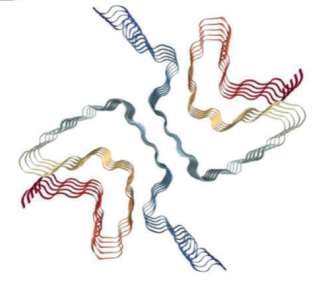

C

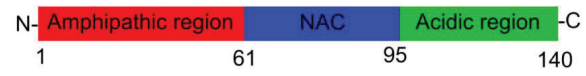

Figure 25.5 a-synuclein structure. (A) Monomeric and (B) fibrillar a-synuclein. Images created using the Protein Data Bank NGL Viewer from 1XQ8 and 6FLT. (C) A schematic of a-synuclein domains.

et al., 2006), which globally disrupts ubiquitindependent proteasomal targeting.

$\alpha$-synuclein can be mono-SUMOylated and lacks detectable poly- or multi-SUMOylation (Dorval and Fraser, 2006; Oh et al., 2011). MonoSUMOylation occurs at one of two putative SUMO consensus motifs, lysine 96 or lysine 102 (Dorval and Fraser, 2006; Oh et al., 2011; Krumova et al., 2011), and does not compete for ubiquitination at these residues (Krumova et al., 2011). Thus far, we know that $\alpha$-synuclein is SUMOylated by E3 hPc2 (Oh et al., 2011) and that Lewy Bodyderived $\alpha$-synuclein is conjugated to SUMO2 in transgenic mouse models (Pounteny et al., 2005; Krumova et al., 2011; Oh et al., 2011). Interestingly, SUMOylation of recombinant and overexpressed $\alpha$-synuclein was found to increase solubility (Krumova et al., 2011; Shahpasandzadeh et al., 2014). Indeed, in vitro SUMO1-conjugation of even 50\% of $\alpha$-synuclein was sufficient to block fibrillization with percentages as low as $10 \%$ substantially delaying fibrillization (Krumova et al., 2011). When SUMOylation of $\alpha$-synuclein is hindered in yeast, cell, and animals models, neurotoxicity is promoted by increased fibrillar/aggregate formation (Krumova et al., 2011; Shahpasandzadeh et al., 2014).

Generally, monoubiquitination of $\alpha$-synuclein promotes aggregation (Nonaka et al., 2005; Lee et al., 2008) while monoSUMOylation promotes solubility (Krumova et al., 2011) and polyubiquitination drives protein degradation via the UPS (Lee et al., 2009). Ubiquitination and SUMOylation of $\alpha$-synuclein are likely independent processes, and occur on different lysine residues (Kim et al., 2011).

\section{Parkinson's disease}

Autosomal-dominant Parkinson's disease arises due to missense mutations and increased expression of $\alpha$-synuclein (Polymeropoulos et al., 1997; Krüger et al., 1998; Zarranz et al., 2004), which results in the selective degeneration of dopaminergic neurons of the substantia nigra pars compacta to the striatum. Aggregates of $\alpha$-synuclein cause Lewy body formation in late stages of the disease. These $\alpha$-synuclein-rich Lewy bodies are the major histopathological hallmark of Parkinson's disease (Spillantini and Goedert, 2000).

A K96R/K102R $\alpha$-synuclein rodent model of Parkinson's disease exhibits exacerbated neuronal toxicity and neurodegeneration (Krumova et al., 2011). By mutating the lysine residues at 96 and 102, $\alpha$-synuclein can no longer be SUMOylated. Recall that lysine 96 and 102 are part of SUMO consensus motifs, and that monoSUMOylation of $\alpha$-synuclein drives solubility (Dorval and Fraser, 2006; Kim et al., 2011; Krumova et al., 2011). Thus, it is possible that an inhibition of $\alpha$-synuclein monoSUMOylation is driving Parkinson-like neurodegenerative effects in this rodent model of Parkinson's disease.

Another element of Parkinson's disease that links ubiquitination to pathology is the E3 ubiquitin ligase parkin. The PARK2 gene produces parkin and the PARK2 genetic mutation is one of the most commonly known genetic causes of early-onset Parkinson's disease, suggesting that ubiquitination may play a critically important role in the disease. However, early onset Parkinson's disease pathology does 
not include $\alpha$-synuclein-rich Lewy body deposits. Instead, disruption in parkin function is linked to inhibited mitochondrial function (Keeney et al., 2006) and increased tumorigenesis (Veeriah et al., 2010).

\section{Multiple systems atrophy}

Multiple systems atrophy (MSA) is a non-heritable neurodegenerative disease, characterized by Parkinsonism, ataxia, and hypotension (Graham and Oppenheimer, 1969). In MSA, neurodegeneration is observed in the substantia nigra, pons, inferior olive, and cerebellum (Matsuo et al., 1998). A neuropathological hallmark of the disease is $\alpha$-synuclein-rich aggregates in oligodendrocytes, called coiled bodies (Papp et al., 1989). MSA aggregates label positively for SUMO1 (Pountney et al., 2005) and ubiquitin, including various amyloidogenic proteins (Lantos, 1989; Sakamoto et al., 2005). High molecular weight $\alpha$-synuclein oligomers also label robustly with ubiquitin (Dickson et al., 1999) in the disease.

Thus far, the influence of ubiquitination and SUMOylation on MSA $\boldsymbol{\alpha}$-synuclein species is undetermined. However, similar themes across synucleinopathies arise. We previously discussed the role of monoubiquitination in $\alpha$-synuclein aggregation. Perhaps coiled bodies of MSA are the downstream product of monoubiquitinated $\alpha$-synuclein. Another plausible theory is that $\alpha$-synuclein is monoSUMOylated and polyubiquitinated as a method of deterring toxic peptide aggregation, by regulating solubility and targeting $\alpha$-synuclein to the proteasome. As mentioned previously, the UPS can target substrate proteins to inclusion bodies (Kawaguchi et al., 2003; Hao et al., 2013; Schipper-Krom et al., 2014) and may provide a mechanism of containing toxic protein that is too aggregated to be efficiently degraded by the proteasome (Ma and Lindquist, 2002).

\section{Dementia with Lewy bodies}

$\alpha$-synuclein inclusion bodies, called Lewy bodies, are the major histopathological hallmark of Dementia with Lewy Bodies (DLB) (Spillatini and Goedert, 2000), a form of dementia that is characterized by delirium, hallucinations, and Parkinsonism (Neef and Walling, 2006). DLB patients show SUMO1 immunolabelling of Lewy bodies
(Pountney et al., 2005), as well as ubiquitin labelling (Tofarist et al., 2003).

Similar to MSA, the PTMs of DLB $\alpha$-synuclein species are not well understood. However, the SUMO1- and ubiquitin-labelling of Lewy bodies bolsters our hypothesis that monoSUMOylation and polyubiquitination of $\alpha$-synuclein is a cellular method of regulating toxic peptides.

\section{Amyotrophic lateral sclerosis}

Amyotrophic lateral sclerosis (ALS) is a degenerative motor neuron disease which leads to paralysis and ultimately death of the individual. While most cases are sporadic, there exists a familial autosomal dominant version of the disease which disrupts the gene encoding copper-zinc superoxide dismutase (SOD1) (154,155) (Fig. 25.6; Elam et al., 2003; Branci et al., 2009; Rose et al., 2018). As many as 119 SOD1 mutations have been linked to familial ALS (Rosen et al., 1993; Anderson, 2006), which is characterized by misfolding and aggregation of SOD1 to produce a cytotoxic gain-of-function conformation and proteinaceous intracellular inclusions (Bruijn et al., 1998; Watanabe et al., 2001; Son et al., 2003). Toxic SOD1 is amyloidogenic, as identified by Thioflavin $\mathrm{T}$ binding, transmission electron microscopy, and nuclear magnetic resonance (Khan et al., 2017).

Also within the proteinaceous intracellular inclusions of ALS is the RNA- and DNA-binding protein TAR DNA-binding protein 43 (TDP-43). Specifically, a missense mutation in TARDBP causes a truncated TDP-43 lacking the C-terminal domain (TDP-S6), leading to TDP-43 aggregation in ALS and other RNA-binding protein-based disorders (Sreedharan et al., 2008; Van Deerlin et al., 2008; Kabashi et al., 2008). TDP-43 aggregates are amyloidogenic, as identified by Thioflavin $\mathrm{T}$ binding, amyloid-immunolabeling, and $\mathrm{x}$-ray scattering (Vogler et al., 2018).

Finally, Fused in Sarcoma (FUS) has been implicated in inclusion formation in a small percentage of ALS cases (Kwiatkowski et al., 2009; Vance et al., 2009). FUS mutations are autosomal dominant and are found in familial ALS and a subset of Frontotemporal Dementia (FTD) and Frontotemporal Lobar Degeneration (FTLD) patients (Sharma et al., 2016). Like SOD1 and TDP-43, FUS is an amyloidogenic protein, as 
A

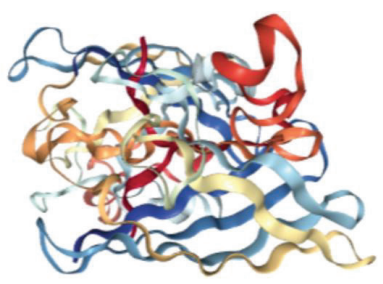

B

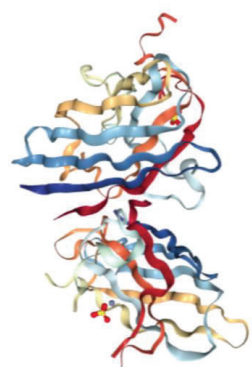

C

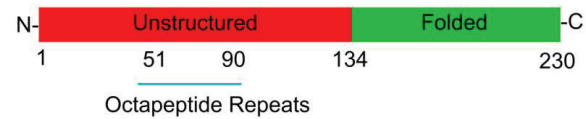

Figure 25.6 SOD1 structure. (A) Wild-type dimer SOD1 and (B) the ALS-mutant S134N dimer SOD1. Images created from the Protein Data Bank NGL Viewer from 3ECU and 1OZU. (C) A schematic of monomeric SOD1.

indicated by Thioflavin $\mathrm{T}$ binding, Congo Red birefringence, transmission electron microscopy, and nuclear magnetic resonance (Murray et al., 2017).

\section{SOD1}

SOD1 inclusion bodies are prominent in many ALS cases. Inclusion body-bound SOD1 can be SUMOylated, and ubiquitin protein is a common component of these aggregates (Watanabe et al., 2001; Howland et al., 2002; Lin et al., 2005; Fei et al., 2006; Niikura et al., 2014). Although found in close proximity within inclusion bodies, the extent of SOD1 ubiquitination is unknown. However, mutant SOD1 is believed to disrupt the UPS in ALS (Cheroni et al., 2009).

SOD1 SUMOylation is much better understood. Specifically, SOD1 undergoes SUMO1-conjugation (Fei et al., 2006) most prominently at lysine 75, followed by lysine 9 (Fei et al., 2006; Niikura et al., 2014). SUMO1-conjugation of SOD1 stabilizes the protein and leads to protein aggregation, and overexpression of SUMO1 in a cell system leads to increased SUMOylation and SOD1 aggregate deposition (Fei et al., 2006).

When SUMO2 and SUMO3 are overexpressed in cells, there is no observable change in SOD1 aggregation (Fei et al., 2006). However, the most common SOD1 mutations found in familial ALS, those at G93 and G85, undergo SUMO2 and SUMO3 SUMOylation (Niikura et al., 2014). Thus, studies on SUMO2- and SUMO3- conjugation of SOD1 are limited to mutated versions of the protein. The lysine 75 site, like with SUMO1, appears most important for SUMO2- and
SUMO3-conjugation (Niikura et al., 2014). When ALS-linked mutant SOD1 is expressed alongside overexpression of SUMO3, increased aggregation is observed (Niikura et al., 2014). If lysine 75 is mutated, there is a significant reduction to the extent of SUMO3-induced aggregation (Niikura et al., 2014).

SOD1 is observed in ALS inclusion bodies. Physiological SOD1 can be SUMO1-conjugated, and this increases the propensity for SOD1 aggregation (Fei et al., 2006; Niikura et al., 2014). Mutant SOD1 can be SUMO1-, SUMO2-, and SUMO3- conjugated; these modifications increase protein aggregation as well (Fei et al., 2006; Niikura et al., 2014). Although capable of SUMO-driven aggregation physiologically, mutated SOD1 has a correlative increase in chances of being SUMOylated and increase in aggregation. It is possible that the increased propensity of SOD1 aggregation in ALS is directly linked to the opening of SUMO consensus motifs in mutated SOD1.

TDP-43

TDP-43 is a DNA- and RNA-binding protein encoded by the TARDBP gene and is often associated with intracellular inclusions found in ALS. TDP-43 aggregation is also associated with Frontotemporal lobar degeneration (FTLD) (Arai et al., 2006; Neumann et al., 2006). Functionally, TDP-43 is found in the nucleus and is involved in RNA transcription, alternative RNA splicing, microRNA processing, and regulation of mRNA stability (Buratti et al., 2001; Wang et al., 2004; Mercado et al., 2005; Strong et al., 2007). In the diseased state, TDP-43 aggregates are involved in degeneration 
and neuronal death, although the detailed mechanisms remain unclear (Cairns et al., 2007; Forman et al., 2007). From studies using yeast and human cells to model the disease, the current hypothesis states that diseased TDP-43 is linked to toxic gainof-function mechanisms (Johnson et al., 2008; Zhang et al., 2009). In the pathological system, TDP-43 leaves the nucleus for the cytoplasm and aggregates into toxic oligomers, likely at membraneless organelle hubs such as stress granules (Taylor et al., 2002; Ross and Poirier, 2004; Dewey et al., 2012). Various isoforms of TDP-43 exist and the form most linked to ALS, TDP-S6, is much more likely to move out of the nucleus and aggregate than the full-length protein (Seyfried et al., 2010).

TDP-43 is the dominant aggregated species of ALS inclusion bodies and is often polyubiquitinated and hyperphosphorylated in either the full-length or truncated form (Rutherford et al., 2008; Kim et al., 2010). Quantitative proteomics has identified increased ubiquitination and SUMO2/3-conjugation of the insoluble species, with lysine 48 and lysine 63 appearing to be the target sites (Olsen et al., 2006). It is hypothesized that $\mathrm{K} 48$ and $\mathrm{K} 63$ are sites of ubiquitin and SUMO competition; however, further data are needed to investigate this speculation.

Interestingly, SUMOylation may drive mutant TDP-43 localization and competition of moiety-conjugation could play a role in pathogenesis. TDP-S6 nuclear inclusions immunolabel for SUMO2/3, but cytosolic inclusions do not (Seyfried et al., 2010). Both nuclear and cytosolic inclusions immunolabel for ubiquitin (Seyfried et al., 2010). Perhaps ubiquitination is a general method for targeting toxic TDP-43 to the proteasome, but deSUMOylation is necessary for the shuttling of the protein.

\section{FUS}

FUS is a DNA- and RNA binding protein which functions to promote annealing of complementary DNA strands and plays important roles in transcription and splicing (Dormann and Haass, 2011). A small group of Frontotemporal Lobar Dementia (FTLD) and ALS cases have FUS in neuronal and glial inclusions (Neumann et al., 2009; Mackenzie et al., 2011). Interestingly, pathogenic FUS is often localized to the cytoplasm and largely avoids the nucleus (Dormann and Haass, 2011). Although functional FUS does shuttle between the nucleus and cytoplasm, it plays primary roles in the nucleus and cytoplasmic localization is often associated with disease.

FUS and FUS-rich inclusions are ubiquitinated in disease (Neumann et al., 2009; Deng et al., 2010; Seelaar et al., 2010; Dormann and Haas, 2011; Farrawell et al., 2015). Other important post-translational modifications to FUS, such as phosphorylation and methylation, also play important roles in FUS toxicity and conformation, but this is beyond the scope of this chapter (Rhoads et al., 2018). In silico analysis and mass spectrometry identifies the C-terminus, specifically the RNA Recognition Motif (RRM), as being the domain of ubiquitination (Farrawell et al., 2015). We do not yet understand the extent of FUS SUMOylation.

\section{Alzheimer's disease and tauopathies}

Alzheimer's disease $(\mathrm{AD})$ is the most prevalent neurodegenerative disorder among the ageing population and is characterized by a progressive cognitive decline leading to dementia, and deficits in language and fine movements (Blennow et al., 2006; Goedert and Spillantini, 2006). The cognitive decline is due to severe synaptic dysfunction, starting in the entorhinal cortex and progressing through the hippocampus and into the cerebral cortex (Van Hoesen et al., 1991). In late stages of the disease, synaptic dysfunction progresses to widespread neuronal death. The hallmarks of the disease are two-fold: senile plaques, composed of $\beta$-amyloid, and neurofibrillary tangles, composed of hyperphosphorylated tau (Tiraboschi et al., 2004; LaFerla et al., 2007).

Before focusing specifically on the amyloids involved in Alzheimer's disease, i.e. $\beta$-amyloid and tau, it is worth noting the strong evidence to support general dysregulation of SUMOylation in the disease. We also note that there exist discrepancies across models used, between labs, and that some alterations in SUMOylation may be due to ageing and not Alzheimer's disease. The most compelling data to suggest age influences SUMOylation comes from Stankova and colleagues (2018). They created a novel animal model of Alzheimer's disease with a SUMO1 knock-in. Data from these animals suggest that SUMO1 increase is related more to the normal ageing process than to the increase of amyloid burden (Stankova et al., 2018). Indeed, genetic 
studies in sporadic late-onset Alzheimer's disease and mild cognitive impairment patients found an association between a single nucleotide polymorphism in Ubc9 and SAE2 (Grupe et al., 2007; Ahn et al., 2009; Corneveaux et al., 2010), which would lead to dysregulation of the SUMOylation pathway. Along these lines, it is hypothesized that SUMO2conjugation could be beneficial against age-related memory loss and that this benefit may extend to Alzheimer's disease (Feligioni et al., 2015).

High molecular weight SUMO2 (>75 kDa) levels are decreased in the hippocampus of $\mathrm{Alz}$ heimer's disease patients (Lee et al., 2014), and a significant down-regulation in the deSUMOylation enzyme SENP3 has been detected in the parietal lobe of Alzheimer's disease patient brains (Lee et al., 2013). The importance of SUMOylation and ubiquitination of APP is also suggested from the genetics of familial Alzheimer's disease. First, the autosomal dominant Swedish early-onset familial form of the disease contains a well characterized mutation on APP at lysine 595 (Mullan et al., 1992). Second, the Korean familial form contains a single nucleotide polymorphism in the E2 enzyme Ubc9 (Ahn et al., 2009). Various genome-wide association studies have attempted to find genetic links to sporadic cases of Alzheimer's disease. Two separate studies found a single nucleotide polymorphism on a gene that maps to SUMO-activating enzyme subunit 2 (SAE2) (Grupe et al., 2007; Corneveaux et al., 2010). Finally, single nucleotide polymorphisms were found in the gene which encodes for Ubc9 in late-onset, sporadic Alzheimer's disease (Lee et al., 2013) and in the gene which encodes for ubiquilin, a ubiquitin-binding shuttle factor involved in shuttling polyubiquitinated proteins to the proteasome (Bertram et al., 2005).

Transgenic animal models have also offered a critical tool to understanding SUMOylation in Alzheimer's disease. In the Tg2576 mouse model, global changes in SUMO1 and SUMO2/3 conjugation levels were observed (McMillan et al., 2011; Nistico et al., 2014). In the hippocampus, levels of ubiquitinated proteins were elevated (McMillan et al., 2011). On further investigation, SUMOylation levels appeared to fluctuate as the disease progressed in Tg2576 animals. At 3 months, considered an early stage of pathology, $\operatorname{Tg} 2576$ mice exhibited increased SUMO1 conjugation compared to age-matched wild-type littermates (Nistico et al., 2014). This increase in SUMO1 conjugation levels remained consistent through 6 months of age. However, by 17 months of age, by which widespread amyloid plaque deposition is apparent, SUMO1 conjugation levels were no longer increased; instead, Ubc9 and SENP1 levels were increased and SUMO2 conjugation levels were decreased in Tg2576 animals (Nistico et al., 2014; Lee et al., 2014). Indeed, SUMO2/3 high molecular weight conjugates $(>75 \mathrm{kDa})$ were found to be reduced by 7 months, just before the age of amyloid plaque onset (Lee et al., 2014). Interestingly, $\beta$-amyloid appears to impair activitydependent SUMOylation in the brain. When Ubc9 is up-regulated, allowing for increased SUMOylation in the system, $\beta$-amyloid-induced deficits to long-term potentiation are rescued (Lee et al., 2014).

A wealth of data from human, animal, and cell studies all indicate that a decrease in high molecular weight SUMO2/3 is Alzheimer's disease-specific. This decrease is likely to be detrimental, considering that increasing SUMOylation rescues diseased long-term potentiation (Lee et al., 2014). It is interesting to speculate what the role of decreased high molecular weight SUMO2/3 proteins could mean in the diseased system. Likely, this is an indication of decreased polySUMOylation. Recall that Ubc9, the only E2 enzyme available in the mammalian SUMOylation pathway, is inhibited in some familial and sporadic cases of Alzheimer's disease (Ahn et al., 2009; Lee et al., 2013). This certainly would reduce SUMOylation of all forms, including polySUMOylation. However, in some models of disease Ubc9 is increased, but high molecular weight SUMO2/3 is still decreased (Lee et al., 2014). There must be more occurring in Alzheimer's disease than just inhibition of polySUMO-chain formation. Indeed, various labs have found that polySUMOylation promotes subsequent ubiquitination and degradation (Lallemand-Breitenbach et al., 2008; Mullen and Brill, 2008; Tatham et al., 2008). Therefore, it is plausible that long polySUMO-chains are created in early stages of disease, as a means of targeting potentially toxic proteins to the proteasome, and thus early stage polySUMOylated proteins have been degraded by late stages of disease. 

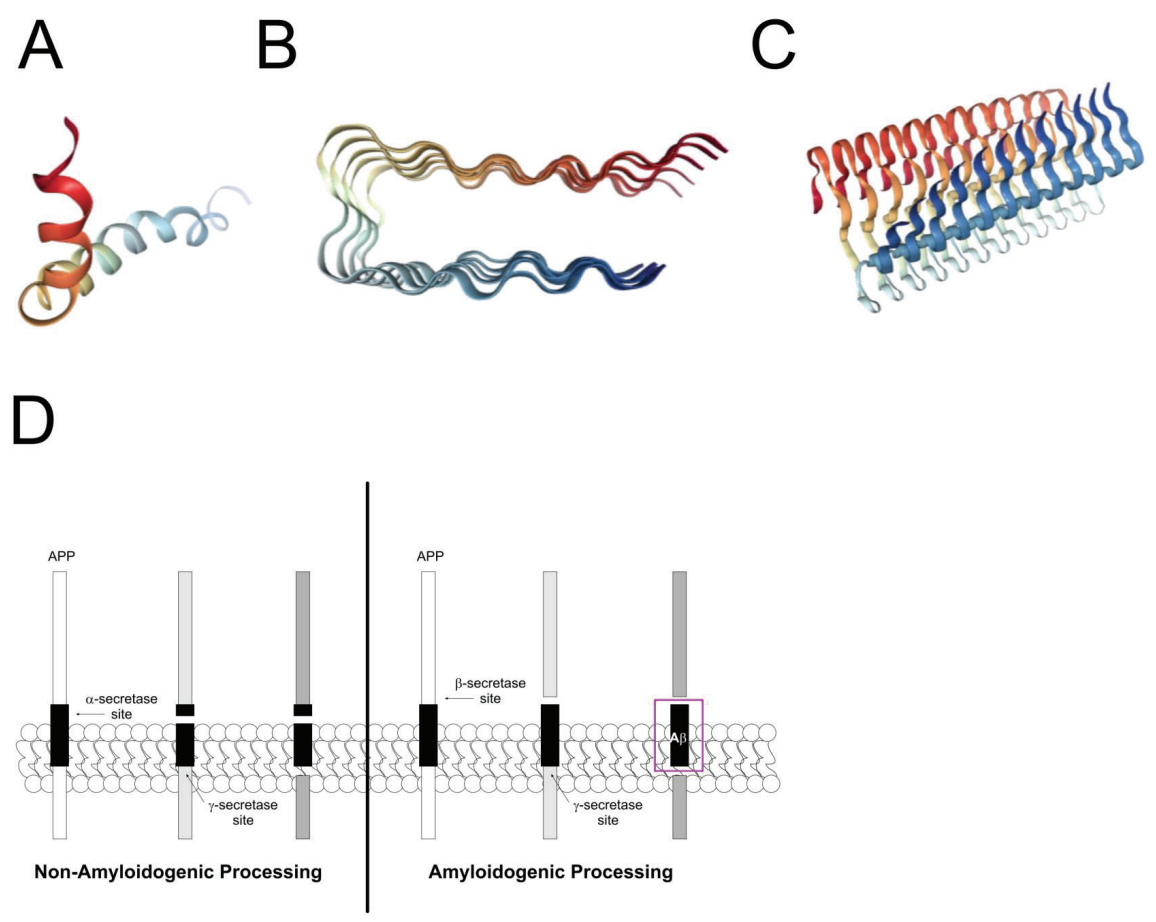

Figure $25.7 \beta$-amyloid structure and APP processing. (A) Monomeric structure of $\beta$-amyloid $1-42$, (B) pentameric structure of $\beta$-amyloid 1-42, and (C) 12-mer structure of $\beta$-amyloid 1-42. Structures 1IYT, 2BEG, and 2MXU were created using the Protein Data Bank NGL Viewer. (D) Toxic $\beta$-amyloid is produced via APP cleavage. Amyloidogenic processing involves $\beta$-secretase cleavage, followed by $\gamma$-secretase cleavage. Nonamyloidogenic processing involves a-secretase cleavage followed by $\gamma$-secretase cleavage.

\section{$\beta$-amyloid}

One of the amyloids present in Alzheimer's disease is $\beta$-amyloid, which is the primary component of senile plaques (Fig. 25.7A,B,C; Crescenzi et al., 2003; Lührs et al., 2005; Xiao et al., 2015; Rose et al., 2018). While $\beta$-amyloid is the toxic amyloid and Amyloid Precursor Protein (APP) is the functional protein from which its cleaved, data suggests that APP is differentially SUMOylated in Alzheimer's disease. The different post-translational modifications of APP lead to a change in cleavage pattern of the protein, affecting the downstream production of $\beta$-amyloid (Zhang and Sarge, 2008).

APP is a type 1 transmembrane glycoprotein. Although the function of APP is currently unknown, it is believed to play a role in formation of the neuromuscular junction, and synaptic transmission, ion channel function (O'Brien et al., 2011). APP is predominantly cleaved through the non-amyloidogenic pathway in healthy brains; the protein is first cleaved by $\alpha$-secretase (also called
ADAM) (Lammich et al., 1999) and then cleaved by $\gamma$-secretases (including the proteins presenilin, PEN2, APH1, niscatrin) (Xia et al., 2000). This process results in products which are thought to be neuroprotective and neurotrophic, and to prevent $\beta$-amyloid formation (Pearson and Peers, 2006). However, APP can also be processed naturally through the amyloidogenic pathway and it is the up-regulation of this processing that increases $\beta$-amyloid in $\mathrm{AD}$. $\beta$-secretase first cleaves $\mathrm{APP}$ (Greenfield et al., 1999; Xia et al., 2000; Xu et al., 2009) followed by $\gamma$-secretase (Xia et al., 2000). $\beta$-amyloid 1-40 and $\beta$-amyloid 1-42 are the dominant products produced via amyloidogenic APP processing, but it is thought that other fragments may be produced through proteolytic degrading enzymes (Kaminsky et al., 2010) (Fig. 25.7D; adapted from Linchtenthaler, 2012).

APP is SUMOylated in vitro by SUMO1 and SUMO2 at lysines 587 and 595, which are near the site of $\beta$-secretase cleavage (Nistico et al., 2014). Hippocampal neurons from Alzheimer's 
disease patients also immunolabelled robustly with SUMO3 (Li et al., 2003). Indeed, mutating lysine at 587 or 595 to arginine produced an APP that could not be SUMOylated (Zhang and Sarge, 2008). These K587R and K595R APP mutants exhibited increased levels of $\beta$-amyloid aggregates, while overexpression of SUMO E2 enzyme decreased levels of $\beta$-amyloid (Zhang and Sarge, 2008). This finding lead researchers to speculate that SUMOylation of APP could act as a protective mechanisms against amyloidogenic processing of APP. Further studies involving the up-regulation of Ubc9 supported this hypothesis, with the resulting decrease in $\beta$-amyloid aggregate levels (Zhang and Sarge, 2008).

APP SUMOylation is convoluted. For example, knockdown of SUMO2 decreased aggregate species but did not appear to have any effect on APP processing ( $\mathrm{Li}$ et al., 2003), suggesting that perhaps there is an indirect role for SUMO2 in APP processing and $\beta$-amyloid production. The authors suggest that this may be through driving $\alpha$ secretase, as opposed to $\beta$ secretase, cleavage of APP ( $\mathrm{Li}$ et al., 2003). Indeed, the $\alpha$ secretase cleavage products had increased SUMO2-modifications (Li et al., 2003). Surprisingly, knockdown of SUMO1 or SUMO2/3 did not affect the levels of APP or $\beta$-amyloid (Dorval et al., 2007). Dorval and colleagues may have identified the critical link; overexpression of SUMO3 protein up-regulated $\beta$-secretase protein levels, likely providing the mechanism for increased $\beta$-amyloid production previously observed in the link between SUMO and $\beta$-amyloid (Dorval et al., 2007). This hypothesis is strengthened by the findings of Zhang and Sarge (2008), who found that overexpression of APP and SUMO3 lead to an increase in $\beta$-amyloid production (Zhang and Sarge, 2008). Yun and colleagues found similar results with SUMO1, detecting a direct link between SUMO1 depletion and decreased $\beta$-amyloid 1-40 levels (Yun et al., 2013).

Although the extent of APP SUMOylation is unknown, polySUMOylation has been postulated. Tatham et al. (2001) immunoprecipitated APP from mouse brain and discovered that the protein was SUMOylated by both SUMO 1 and SUMO2/3 (Gocke et al., 2005). While the extent of endogenous SUMOylation of APP is undetermined, research has provided insight into the importance of poly- versus monoSUMOylation of APP with regards to $\beta$-amyloid production. HEK293T cells were transfected with APP and a SUMO3 variant which could not produce SUMO chains, but could still mono-SUMOylate (Dorval et al., 2007). MonoSUMOylation of APP resulted in an increase in $\beta$-amyloid generation, leaving the researchers to speculate that polySUMOylation may negatively regulate $\beta$-amyloid production (Dorval et al., 2007).

Ubiquitination of $\beta$-amyloid has been studied using a transgenic mouse model of Alzheimer's disease. In this study, the APPswe/PS1 mouse model was crossed to a $\mathrm{UBB}+1$ mouse. The $\mathrm{UBB}+1$ mutant inhibits the ubiquitin-proteasome system, and so this bigenic model allows for the study of the ubiquitin-proteasome system on $\beta$-amyloid. Looking at various ages, researchers found a significant decrease in $\beta$-amyloid deposition and in soluble $\beta$-amyloid (1-42) (van Tijn et al., 2012). The reduction in amyloid deposition was transient, only lasting until 9 months of age (van Tijn et al., 2012). Intriguingly, the animals still expressed astrogliosis and were as functionally impaired as APPswe/PS1 age-matched controls (van Tijn et al., 2012).

Although complex, it appears that $\beta$-amyloid production is influenced by APP SUMOylation. Reduction of SUMO1, SUMO2, or SUMO3 leads to decreased aggregated $\beta$-amyloid (Li et al., 2003; Dorval et al., 2007; Yun et al., 2013). Furthermore, polySUMOylation may play a role in negatively regulating $\beta$-amyloid production (Dorval et al., 2007). However, it is unclear if simply an increase in available SUMO lead to the increase in peptide as opposed to the disruption of polySUMOylation. Ubiquitination of APP is less understood than SUMOylation. When the UPS is inhibited, Alzheimer's disease-models display less soluble and insoluble $\beta$-amyloid (van Tijn et al., 2014). However, the possibilities of off-target effects are great, and the question still exists of direct APP ubiquitination.

\section{Tau}

The second amyloid present in Alzheimer's disease is tau, the primary component of neurofibrillary tangles and the neuropathological hallmark of tauopathies. Functionally, tau helps to stabilize microtubules and plays an important role in axon development (Mietelska-Porowska et al., 2014). In Alzheimer's disease and other tauopathies, tau 
becomes hyperphosphorylated. The hyperphosphorylated tau is prone to amyloid fibrillization, leading to neurofibrillary tangle formation, and to disruption of its native function in microtubule stabilization (Mietelska-Porowska et al., 2014) (Fig. 25.8; Fitzpatrick et al., 2017; Rose et al., 2018).

While phosphorylation remains the best-characterized post-translational modification of tau, tau also undergoes SUMOylation and ubiquitination (Dorval and Fraser, 2006; Morris et al., 2015). Tau ubiquitination was identified by mass spectrometry of paired helical filaments isolated from Alzheimer's disease brain (Morishima-Kawashima et al., 1993; Cripps et al., 2006) and from mouse brain tissue (Morris et al., 2015). This ubiquitination leads to downstream proteasome degradation of tau (David et al., 2002), although, tau can also be degraded through the ubiquitin-independent proteasome system (Shimura et al., 2004).

Tau can also be SUMOylated. Specifically, tau is SUMOylated at lysine 340, which is within the fourth microtubule binding repeat domain (Luo et al., 2014) (Fig. 25.8B; adapted from Fitzpatrick et al., 2017). Therefore, it is hypothesized that on tau release from microtubules, the K340 residue is accessible to SUMOylation enzymes (Luo et al., 2014). Indeed, this hypothesis was tested by applying colchicine to induce microtubule depolymerization and increase the available tau pool. The available tau exhibited a significant increase in SUMOylation (Luo et al., 2014). When SUMO and human tau are overexpressed in cells, high molecular weight bands of SUMOylated tau species increase (Dorval et al., 2007; Luo et al., 2014). This increase is robust for SUMO1 and was observed for
SUMO2 and SUMO3 as well (Dorval et al., 2007; Luo et al., 2014).

Furthermore, in vitro studies indicate that SUMOylation of tau elevates levels of tau phosphorylation (Neddens et al., 2018), leading to an increase in cytotoxicity. When overexpression of both tau and SUMO1 occur in HEK293T cells, tau undergoes a significant increase in phosphorylation at Thr205, Ser214, Thr231, Ser262, Ser396, and Ser404 (Yu et al., 2009). To confirm linkage of tau SUMOylation and phosphorylation, researchers inhibited protein SUMOylation using ginkgolic acid and observed reduced phosphorylation of tau (Yu et al., 2009). Another group's findings further strengthen the link between tau SUMOylation and phosphorylation; when a SUMO-conjugation deficient tau mutant (K340R) is overexpressed, both SUMOylation and phosphorylation are markedly decreased on tau (Luo et al., 2014).

One report suggests that there is a direct link between the SUMOylation/ubiquitination of tau and its state of solubility. When tau is overexpressed in HEK293T cells, SUMOylation of tau is increased while ubiquitination of tau is decreased. This coincided with an increase in tau aggregation and a decrease in tau degradation (Luo et al., 2014). Studies also indicate an important linkage between tau acetylation and ubiquitination, the importance of which is only just starting to be understood. Ubiquitination sites are often in competition for acetylation, as identified by mass spectrometry (Morris et al., 2015). Tau methylation also appears to compete for two lysine residues, increasing the complexity of modification crosstalk (Morris et al., 2015). When lysine 311 and 281 are mutated so as not to be ubiquitinated, acetylated, or methylated,
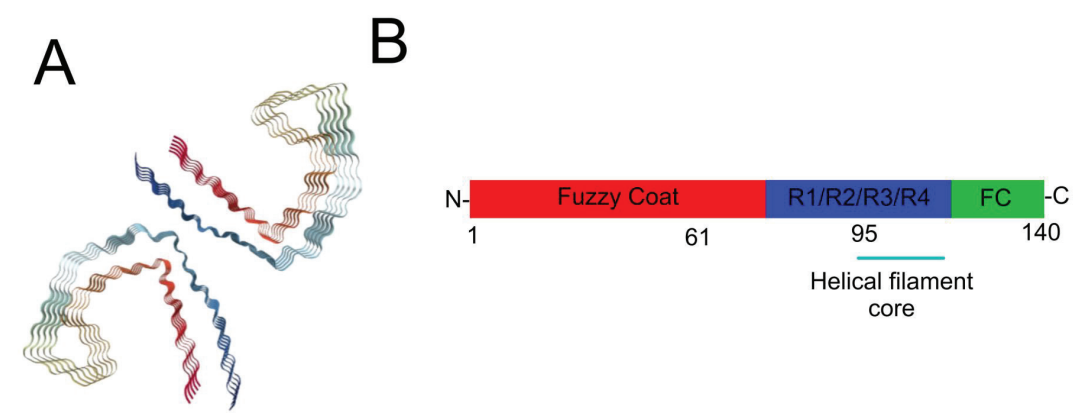

Figure 25.8 Tau structure. (A) Fibrillar tau of microtubule binding regions 3 and 4 and (B) schematic of primary structure of tau. Structure created from the Protein Data Bank NGL Viewer from 503T. 
microtubule binding and protein aggregation decreases, suggesting an important conformational regulatory mechanism at these sites (Morris et al., 2015).

As previously mentioned, neurofibrillary tangles label robustly for ubiquitin (Drummond et al., 2018). Indeed, tau is known to be degraded by the proteasome through both ubiquitin-independent and ubiquitin-dependent processes (David et al., 2002; Cardozo et al., 2002). Data suggest that both neurofibrillary tangles and soluble tau species can be ubiquitin-labelled (David et al., 2002; Cardozo et al., 2002; Drummond et al., 2018). A particularly interesting study found a direct link between cytosolic Ubiquitin-C-terminal Hydrolase L1 (UCHL-1) and a naturally-occurring truncated variant of tau, which is cleaved at aspartic acid 421 by caspases (Corsetti et al., 2015). UCHL-1, which functions as a modulator of ubiquitin homeostasis and controls remodelling of synapses, was found to interact non-physiologically with the truncated tau fragment, contributing to the early synaptotoxicity observed in Alzheimer's disease (Corsetti et al., 2015).

In the case of tau, ubiquitination and SUMOylation appear to work in contrast. This hypothesis comes from the findings that neurofibrillary tangles probe highly positively for ubiquitin, but not for SUMO1 (David et al., 2002; Cardozo et al., 2002; Drummond et al., 2018), and cell studies that observed a link between increased tau aggregation with increased SUMOylation and decreased tau degradation with increased ubiquitination (David et al., 2002; Cardozo et al., 2002). As stated previously for general inclusion body formation, ubiquitination of the substrate drives the toxic protein to degradation. However, if toxic proteins overwhelm the system, ubiquitinated proteins may be left in inclusion bodies as a final attempt to regulate pathogenicity. This may be the case for tau and neurofibrillary tangle formation (David et al., 2002; Cardozo et al., 2002; Drummond et al., 2018). However, recent crosstalk and mutagenesis studies indicate that there may be much more complex signalling pathways at work (Morris et al., 2015).

An equally confounding question is the role of SUMOylation in tau pathogenicity. Unbound tau is more likely to be SUMOylated, and this SUMOylated tau leads to an increase in hyperphosphorylation of the protein and protein aggregation (Köpke et al., 1993; Mandelkow et al., 1994). Perhaps SUMOylation of tau is the first step on the road to fibrillization. Indeed, SUMO-conjugation could provide the critical conformational change needed to create the cross- $\beta$ structure in tau. However, this hypothesis has yet to be tested. Another plausible consideration is that SUMOconjugation allows for exposure of numerous phosphorylation sites that would have otherwise been masked or helps to recruit kinases to tau for increased phosphorylation.

\section{Polyglutamine disorders}

Polyglutamine disorders involve the expansion of a toxic CAG stretch in disease-specific genes. CAG expansion in polyglutamine disorders is familial, with variable $\mathrm{CAG}$ stretches depending on genetic inheritance. On translation, the CAG stretch ultimately becomes a polyglutamine, or polyQ stretch in the effected protein and undergoes a toxic gainof-function (Watase et al., 2002; Yoo et al., 2003). PolyQ rich proteins are prone to aggregation and can result in neuronal inclusions, as hallmarked in polyglutamine disorders (Zoghbi and Orr, 2000; Gatchel and Zoghbi, 2005). These polyglutamine pathologies cause neuronal death in specific brain regions, including the basal ganglia, cerebellum, brainstem, and spinal motor nuclei (Ross et al., 2002).

Aggregation of polyQ proteins is thought to overwhelm the UPS and to compromise essential cellular functions of the machinery (Mayer et al., 1989). Ubiquitination reduces polyQ toxicity, likely by promoting degradation of toxic polyQ proteins. Indeed, when UPS functioning is accelerated, polyQ toxicity lessens (Verhoeft et al., 2002; Michalik and Van Broeckhoven, 2004). This hypothesis is further strengthened by the finding that ubiquitin ligase mutations enhance polyQ toxicity (Saudou et al., 1998; Cummings and Zoghbi, 2000; Fernandez-Funez et al., 2000) and overexpression of the E3 ubiquitin ligase, Parkin, reduces polyQ aggregation and suppresses toxicity (Tsai et al., 2003). However, there is a debate within the field whether polyQ proteins are degraded by the UPS (Venkatraman et al., 2004; Pratt and Rechsteiner, 2008; Juenemann et al., 2013).

Some studies suggest that polyQ proteins can be degraded if in a soluble state (Verhoef et al., 2002; 
Kaytor et al., 2004; Michalik and Van Broeckhoven, 2004; Juenemann et al., 2013; Tsvetkov et al., 2013). Others indicate that the proteasome cannot degrade polyQproteins (Dyer and McMurray, 2001; Jana et al., 2001; Holmberg et al., 2004; Venkatraman et al., 2004). Indeed, in various mouse models of polyQ diseases, there is a lack of UPS impairment with an increase of polyQ proteins (Bence et al., 2001; Jana et al., 2001; Bennett et al., 2005). Instead, work in animal models suggests that polyubiquitin chains on polyQ proteins causes a blockage of the UPS during degradation (Maynard et al., 2009). It is worth noting, however, that a simple blockage of the UPS may not be the only disruption to the UPS in polyQ disease; instead, proteasomal degradation and polyQ protein interaction is likely much more complicated.

Beyond the general effect on the UPS, all major polyglutamine disorders have high immunostaining of neuronal inclusions with SUMO (Ueda et al., 2002; Dorval and Fraser, 2007). Thus, SUMOylation and ubiquitination likely play an important role in polyglutamine diseases.

\section{Huntington's disease}

The neuropathological hallmark of Huntington's disease is Huntingtin ( $\mathrm{Htt})$ with various expansions in the polyQ region of the $\mathrm{N}$-terminal domain (MacDonald et al., 1993). A minimal polyQlength, around 34-45 repeats, must be exceeded for Huntingtin $(\mathrm{Htt})$ to undergo a conformational change to a cross $\beta$ sheet rich amyloid-like state (Poirier et al., 2002; Steffan et al., 2004). Functionally, Htt is neuroprotective and enhances production of neurotrophic factors (Cattaneo et al., 2009). In the disease state, $\mathrm{Htt}$ aggregates and causes neuronal death. It is still unknown whether the pathogenesis of Huntington's disease is due to a gain- or lossof-function of Htt (Bence et al., 2001; Cattaneo et al., 2009). Both full-length and fragment $\mathrm{Htt}$ (Httex1p97QP) have been found in $\mathrm{Htt}$ inclusions, and both contain the polyQ N-terminal domain (Kachman et al., 1996; Davies et al., 1997). These inclusions correlate with increased survival in neurons expressing polyQ Htt (Arrasate et al., 2004), providing strong evidence that proteinaceous inclusions provide a 'dumping ground' for toxic, misfolded polyQ proteins.

Both full-length and fragment $\mathrm{Htt}$ are regulated by post-translational modifications, including ubiquitination (Kalchman et al., 1996; Davies et al., 1997) and SUMOylation (Pennuto et al., 2009; Ehrnhoefer et al., 2011; Zheng and Diamond, 2012). Indeed, when Huntington's disease striatum samples were measured for levels of SUMOylation, the insoluble fraction of proteins had much higher SUMO2- and SUMO1-conjugation than agematched controls (O'Rourke et al., 2013).

Huntingtin protein is SUMOylated on lysine residues in the $\mathrm{N}$-terminus (Steffan et al., 2004). Increased SUMOylation at these residues correlates with increased polyQ-derived toxicity (MacDonald et al., 1993). If SUMOylation sites are disrupted or E3 ligases are down-regulated, $\mathrm{Htt}$ aggregation decreases (Steffan et al., 2004). SUMO2 seems to play a particularly important role in modifying $\mathrm{Htt}$, as a dose-dependent increase in $\mathrm{Htt}$ aggregation is observed (Lee and Goldberg, 1998). Since both full-length $\mathrm{Htt}$ and fragment $\mathrm{Htt}$ share these lysine residues, it is unsurprising that the $\mathrm{Htt}$ fragment can also be SUMO1- and SUMO2-conjugated (O'Rourke et al., 2013). SUMOylation of the Htt fragment appears to stabilize the peptide (Steffan et al., 2004). Furthermore, SUMO1-conjugation to the $\mathrm{Htt}$ fragment increases $\mathrm{Htt}$ accumulation and toxicity, but decreases aggregation of the polyQ protein (Andersen, 2006).

SUMOylation and ubiquitination appear to compete for modification at lysines 6 and 9. While SUMOylation promotes $\mathrm{Htt}$ aggregation, ubiquitination at these same sites promotes solubility (MacDonald et al., 1993). Furthermore, overexpression of ubiquilin, a ubiquitin-binding shuttle factor involved in shuttling polyubiquitinated proteins to the proteasome, has a neuroprotective effect in a mouse model of Huntingtin's disease (El Ayadi et al., 2012).

Generally, it appears that SUMOylation of $\mathrm{Htt}$ leads to increased aggregation and ubiquitination of $\mathrm{Htt}$ leads to increased solubility. As the lysine residues are consistent across full-length and fragmented Htt, both toxic species have similar PTM modifications. An important distinction seems to arise in the SUMO protein being conjugated to $\mathrm{Htt}$. Whereas SUMO1 is found in Htt-rich inclusion bodies and drives the fragment $\mathrm{Htt}$ to be neurotoxic, it likely does not influence $\mathrm{Htt}$ aggregation (Andersen, 2006; O’Rourke et al., 2013; Kunadt et al., 2015). Instead, SUMO2 appears to be the key driving force behind Htt aggregation (Kunadt et al., 
2015). These findings question if monoSUMOylation and polySUMOylation of $\mathrm{Htt}$ drive different functions. While both are neurotoxic, perhaps polySUMOylation is an attempt at cellular protection. Indeed, there is a debate about whether polyQ proteins can be degraded by the proteosome. If possible, research suggests that only soluble polyQ proteins are able to be degraded through these mechanisms (Verhoef et al., 2002; Kaytor et al., 2004; Michalik and Van Broeckhoven, 2004; Juenemann et al., 2013; Tsvetkov et al., 2013). Thus, the cell would need to control toxic polyQ production in some way. We discussed previously that polySUMOylation drives substrates to the UPS, and that the UPS leave non-degradable proteins in inclusion bodies. Thus, it is plausible that polySUMOylation drives inclusion body formation.

This theory becomes even more interesting when ubiquitination, monoSUMOylation, and polySUMOylation are considered together. If the hypothesis stands that polySUMOylation controls non-degradable polyQ proteins by driving inclusion body formation, then where does ubiquitination fit? Likely, soluble polyQ proteins are able to be ubiquitinated and degraded via the UPS. If this is the case, then insoluble polyQ proteins are likely to outcompete ubiquitin and instead be SUMOylated. This then allows the available lysine residues to be mono- or poly-SUMOylated.

\section{Dentatorubral-pallidoluysian atrophy} Dentatorubral-pallidoluysian atrophy (DRPLA) is a neuropathological disorder, characterized by dementia, epilepsy, and disrupted movement. DRPLA arises from a CAG expansion in the gene which encodes atrophin-1 (Yazawa et al., 1995; Schilling et al., 1999), the function of which is currently unknown. However, SUMO1-conjugation of polyQ atrophin-1 increases nuclear inclusion body formation and cell death (Terashima et al., 2002). Indeed, when a conjugation-null SUMO1 mutant is overexpressed with polyQ atrophin-1, inclusion formation is decreased (Terashima et al., 2002).

Currently, the data are too sparse to hypothesize the role of SUMOylation and ubiquitination on atrophin-1.

\section{Spinal and bulbar muscular atrophy}

Spinal and bulbar muscular atrophy (SBMA) occurs when a CAG repeat occurs in the gene which encodes Androgen Receptor, a transcription factor that is stimulated by the androgen hormone (Katsuno et al., 2006). SBMA is an X-linked neurodegenerative disorder which manifests as progressive muscle weakness due to motor neuron degeneration in the brain stem and spinal cord. PolyQ Androgen Receptor can be SUMOylated and ubiquitinated on the same lysine residue (Poukka et al., 2000). Functionally, SUMOylation of Androgen Receptor suppresses its transcriptional activity (Takahashi-Fujigasaki et al., 2001; Nishida and Yasuda, 2002). When SBMA is modelled in Drosophila, inhibition of SUMOylation and ubiquitination of Androgen Receptor increases nuclear and cytosolic inclusion formation and degeneration (Chan et al., 2002). Indeed, when SUMO3 is overexpressed in cells, Androgen Receptors exhibit decreased aggregation and increased solubility (Mukherjee et al., 2009).

Unlike Htt, SUMOylation and ubiquitination of androgen receptor appear to work in concert with each other. Both SUMO- and ubiquitin-conjugation to androgen receptor keep the protein soluble and monomeric (Mukherjee et al., 2009).

\section{Spinocerebellar ataxia types I, III, and VII}

Spinocerebellar ataxia (SCA) is a neurodegenerative disorder characterized by degeneration of Purkinje cells in the cerebellum. The disorder arises from a CAG expansion in the genes which encode the ataxin family of proteins. This family of proteins bind DNA and are involved in various nuclear functions. SCA-I occurs when a polyQ stretch forms in the ataxin-1 protein. Ataxin-1 can be SUMOylated on at least five different lysine residues and when the polyQ region stretches in SCA-I, SUMOylation of ataxin-1 is decreased (Riley et al., 2005). Silencing of SUMO2/3 using siRNA raises levels of ataxin-1 (Guo et al., 2014), and overexpression of SUMO1 reduces SUMO 2/3 conjugation, ubiquitination, and degradation of the protein (Guo et al., 2014). Inhibiting the formation of SUMO chains by overexpressing a chain-deficient SUMO2 KR mutant decreases the SUMO 2/3 conjugated high molecular weight ataxin- 1 species, reduces ubiquitination, and blunts degradation of ataxin-1 (Guo et al., 2014).

When SUMO1 or E2 enzyme Ubc9 is overexpressed, polyQ ataxin-1 aggregation increases (Ryu et al., 2010). Conversely, genetically inhibiting 
ubiquitination enhances polyQ-mediated neurodegeneration in a mouse model of SCA-1 (Cummings et al., 1999) and mutating mouse Usp14, which encodes a deubiquitinating enzyme, leads to ataxia (Chernova et al., 2003). Blocking SUMO 2/3 with an siRNA reduces ubiquitination of ataxin-1, suggesting that the SUMO- and ubiquitination systems are working together (Guo et al., 2014).

Machado-Joseph Disease (MJD), or SCAIII, arises from the aggregation of Ataxin-3. Functionally, ataxin-3 deubiquitinates proteins by disassembling lysine 48- and lysine 63-linked polyubiquitin chains (Winborn et al., 2008). Ataxin-3 interacts directly with the ubiquitin-selective chaperone valosin-containing protein (VCP), which is critical for appropriate proteasomal degradation (Watts et al., 2004). CAG expansion in the gene produces the most common form of autosomal dominant SCA. Indeed, overexpression of polyQ ataxin-3 compromises the ability of the ubiquitin proteasome system to function appropriately (Burnett et al., 2003), whereas expression of ubiquitin ligase Parkin reduces polyQ ataxin-3 toxicity (Tsai et al., 2003; Morishima et al., 2008). Overexpression of the ubiquitin ligase $\mathrm{C}$ terminus of Hsc-70 interacting protein (CHIP) also delays the age at onset of the disease phenotype (Al-Ramahi et al., 2006).

Like Ataxin-1, Ataxin-3 can be SUMOylated. Ataxin-3 has two SUMOylation sites, lysine 166 and lysine 356 (Zhou et al., 2013; Almeida et al., 2015). SUMO1-conjugation to Ataxin-3 results in protein stability, leading to increased toxicity and apoptosis (Zhou et al., 2013). However, Hsp70 chaperone function is able to rescue SUMO-induced polyQMJD degeneration (Besnault-Mascard et al., 2005; Shirakura et al., 2005; Hayashi et al., 2006).

SCA-VII arises from a polyQ stretch of ataxin-7. Ataxin-7 can be SUMO1- or SUMO2-conjugated at lysine 257 (Janer et al., 2010). Both SUMO1and SUMO2- conjugated ataxin-7 are found in inclusion bodies; however, SUMO1-conjugation decreases ataxin-7 aggregate formation (Janer et al., 2010). Mutagenesis of K257 increases levels of SDS-insoluble Ataxin-7 aggregates and increases the amount of caspase- 3 positive cells (Ryu et al., 2010).

SCA-I and SCA-III are similar, in that SUMO1conjugation promotes protein insolubility and neurotoxicity. Thus far, we have considered SUMO1-conjugation as representing monoSUMOylation or multiSUMOylation, as opposed to chained polySUMOylation. If this is true, then the role of SUMO2/3 in SCA-I disease reduction is likely due to polySUMOylation of the protein. Indeed, polySUMOylation and ubiquitination can target substrates to the UPS. In SCA-I, data suggests SUMO2/3- or ubiquitin-conjugation inhibits disease progression, possibly via UPS-driven degradation. Contradictorily, SCA-VII forms aggregate to a lesser extent when conjugated with SUMO1. It is odd that proteins within the same family would have such drastically different functions from the same modification. Ultimately, we are unable to hypothesize why this may be. SCA-VII is less studied than SCA-I and SCA-III, and so the data are much more limited.

\section{Rare disorders}

\section{Neuronal intranuclear inclusion disorder}

Neuronal intranuclear inclusion disorder (NIID) is a rare neurodegenerative disease that affects both the central and peripheral nervous system. Characterized by the presence of neuronal intranuclear inclusions, the symptoms include ataxia and movement disorders which eventually develop into dementia (Sung et al., 1980). While most cases of NIID are sporadic, some familial cases do exist as autosomal dominant disease (Kimber et al., 1998; Zannolli et al., 2002).

The neuronal intranuclear inclusions which hallmark this disease stain strongly for SUMO and ubiquitin reactivity across all forms of the disease, including familial, juvenile, and sporadic (Pountney et al., 2003; McFadden et al., 2005; TakahashiFujigasaki et al., 2006). On further investigation, multiple SUMO substrates have been localized to inclusions from diseased patient tissues. For example, localization studies using sporadic and familial NIID tissues suggest that the SUMO substrates histone deacetylase 4 (HDAC4) and promyelocytic leukaemia (PML) are components of the neuronal intranuclear inclusions (Takahashi-Fujigasaki et al., 2006). Indeed, the highly SUMOylated RanGAP1 has also been localized to neuronal intranuclear inclusions in familial NIID tissue (TakahashiFujigaskai et al., 2006). 
There appears to be an interesting overlap of NIID nuclear inclusions with aggregation-prone proteins of other neurodegenerative diseases. For example, ataxin-3, ataxin-1, and multiple polyglutamine disorder-related proteins are commonly found within nuclear inclusions (Lieberman et al., 1998, 1999; Zoghbi and Orr, 2000). Since there is no defining toxic protein identified with NIID, these inclusions likely arise from a general misregulation of SUMO- and ubiquitination. Thus, it is unsurprising that other aggregation-prone proteins appear in NIID inclusions with various levels of SUMO- and ubiquitination.

\section{Prions}

While many human prion diseases exist, this section focuses on the priogenic protein $\operatorname{PrP}$ which is found in kuru, Creutzfeldt-Jakob disease, fatal familial insomnia, and Gerstmann-StrausslerScheinker syndrome. Genetic mutations have been found in the PrP gene of the familial forms of these diseases. The first genetic linkage to prion disease was found in GSS, which contains a P102L mutation in the PrP gene (Chernoff et al., 1995). Since this finding, 40 more mutations have been found in the PrP gene across all human prion protein diseases (Mead, 2006; van der Kamp et al., 2009). These genetic mutations have been linked to the priogenic conversion of PrP to pathogenic PrPsc, causing loss of prion protein function, increased toxicity, and increased transmissibility.

Like most other proteinaceous inclusions, PrP aggregates are ubiquitinated (Piccardo et al., 2014) and there exists a correlation between elevated levels of ubiquitin-conjugated protein and reduced proteasomal function (Kang et al., 2004; McKinnon et al., 2016). Ubiquitination of prion aggregates is believed to occur once PrP has converted to the priogenic PrPsc form (Kang et al., 2004). This is linked to the ubiquitin-proteasome system, as identified by expression of the dominant negative mutant of USP14, a deubiquitinating enzyme that controls trimming of polyubiquitin chains and regulates the proteasomal process. When the dominant negative USP14 is expressed in a prion disease-model system, pathogenic prion protein was reduced (Homma et al., 2015). Indeed, expression of wild type USP14 increased pathogenic prion protein (Homma et al., 2015).
While the ubiquitin proteasome system appears to be involved in providing a 'dumping ground' for most toxic amyloid and amyloid-like proteins, prions appear to affect the function of the UPS. Wild-type prion protein is degraded in a ubiquitindependent manner (Yedidia et al., 2001). However, mutant prion protein oligomers directly bind to and inhibit the activity of the proteasome (Kristiansen et al., 2007; Deriziotis et al., 2011).

The SUMO pathway is also involved in prion diseases. Specifically, in Creutzfeldt-Jakob disease, SUMO2/3 protein levels are decreased in patients (Karu et al., 2014). The toxic PrP protein is also believed to be a SUMO target due to its involvement in various SUMOylation-dependent pathways; however, SUMOylation of PrPc has yet to be determined. Perhaps, as mentioned in previous sections, polySUMOylation is negatively impacted in prion diseases. This would also lead to a decrease in PrPsc targeting to the proteasome, which is already negatively impacted in prion diseases.

\section{Functional amyloid-like proteins.}

\section{Mammalian}

\section{Cytoplasmic polyadenylation element binding protein 3}

Cytoplasmic polyadenylation element binding protein 3 (CPEB3) is an RNA-binding protein that undergoes stimulus-dependent conformational and functional change. In its basal state, CPEB3 is soluble and functions as a translation inhibitor (Fioriti et al., 2015). On neuronal stimulation, CPEB3 converts to an insoluble translation promoter (Fioriti et al., 2015). The insoluble, translation promoter form of CPEB3 is necessary for long-term memory maintenance (Fioriti et al., 2015). From studies conducted under denaturing conditions, CPEB3 appears to form amyloid-like fibrils (Stephan et al., 2015) and when expressed in yeast, exhibits prionlike transmissibility (Si et al., 2010).

Work from our lab has shed insight into cellular regulation of $\mathrm{CPEB} 3$ structure and function. CPEB3 is SUMOylated in the basal state and deSUMOylated when functioning to promote translation (Drisaldi et al., 2015). There is a cyclical quality to CPEB3 deSUMOylation and SUMO 
protein production; SUMO2 mRNA appears to be a CPEB3 target (Drisaldi et al., 2015). Interestingly, recent work from our lab has further validated the hypothesis that SUMOylation renders CPEB3 soluble and functionally inhibitory. SUMOylated CPEB3 is retained in the membrane-less organelle $\mathrm{P}$ body, the function of which is to degrade mRNAs (Ford et al., 2019). However, on chemical long-term potentiation (cLTP) stimulation, CPEB3 exits the P Body and enters the polysome for mRNA translation (Ford et al., 2019). In vitro, SUMOylated and RNA-bound CPEB3 undergoes phase separation and forms $\mathrm{P}$ body-like droplets (Ford et al., 2019).

Beyond SUMOylation, ubiquitination also plays an important role in CPEB3 structure and function regulation. On synaptic activation, levels of the E3 ubiquitin ligase Neuralized (Neur1) increase (Pavlopoulos et al., 2011). This increase in Neurl1 is necessary for healthy memory function, by facilitating synthesis of proteins involved in synaptic plasticity and synaptic remodelling (Pavlopoulos et al., 2011). The effect of Neurll on protein synthesis is tied to ubiquitination of CPEB3; when ubiquitinated by Neurl1, CPEB3 undergoes a functional conversion to promote translation of target mRNAs (Pavlopoulos et al., 2011).

Our lab is excited to continue the investigation into ubiquitination and SUMOylation of CPEB3, and currently believe that a SUMO-ubiquitin switch may be involved in altering translation functionality.

\section{La}

$\mathrm{La}$ is an RNA-binding protein which binds and traffics various axon-bound mRNAs (Wolin and Cedervall, 2002). The successful binding and trafficking of mRNAs to La is critical for growth-cone guidance, axonal regeneration, and synaptic plasticity (Wolin and Cedervall, 2002). SUMOylation of La directly influences its role in these neuronal functions (van Niekerk et al., 2007) and disrupted SUMOylation of La has been discovered in various cancer cell lines. La depletion and mistrafficking appears to impair cell proliferation in cancer; however, the exact mechanism is still unclear (Kota et al., 2018).

Both SUMO-1 and SUMO-2/3 can modify La in an overexpression system, although endogenous
SUMOylation is still unknown (van Niekerk et al., 2007). Non-SUMOylated La binds kinesin and La SUMOylated at lysine 41 binds dynein; thus, SUMOylation plays an important role in axonal trafficking (van Niekerk et al., 2007). Specifically, non-SUMOylated La moves anterograde, while SUMOylated La moves both anterograde and retrograde along the axon (van Niekerk et al., 2007). Beyond trafficking, SUMOylation also enhances mRNA binding to La (Kota et al., 2016). Indeed, when mutated to lack SUMOylation sites, mutant $\mathrm{La}$ is incapable of binding target mRNAs (Kota et al., 2016).

\section{Mitochondrial anti-viral signalling protein and RIG-1}

Mitochondrial anti-viral signalling protein (MAVS) is a component of an anti-viral immune response. In the signalling cascade, MAVS is downstream of receptor RIG-1 and functions to activate kinases that ultimately activate the transcription factors NF-kB and IRF3 (McWhirter et al., 2005). On activation by lysine 63-polyubiquitinated RIG-1, MAVS undergoes a gain-of-function conformation change to a fibrillar state (Hou et al., 2011). These MAVS fibrils consist of three-stranded helixes (Xu et al., 2014) as opposed to the classic cross $\beta$ sheet of true amyloids. The polyubiquitination of RIG-1 plays the critical role of exposing the CARD domain of the protein, allowing for downstream interaction with MAVS, fibrillization of MAVS, and further activation of the signalling cascade (Hou et al., 2011). The same E3 that ubiquitinates RIG-1, TRIM25, also ubiquitinates MAVS at lysine 7 and 10 (Castanier et al., 2012). The RING finger protein 5 (MARCH5) ubiquitinates filamentous MAVS, targeting the protein to proteasomal degradation (Yoo et al., 2015).

MAVS is an interesting example of how E3 ubiquitination targets the same protein in different conformations, driving various downstream effects. For example, TRIM25 ubiquitination of MAVS is likely the E3 involved in CARD domain exposure and downstream fibril formation. Whereas MARCH5 specifically targets filamentous MAVS for degradation. It is still unknown if TRIM25 and MARCH5 ubiquitinate different residues and if there is a difference in monoubiquitination or polyubiquitination. 


\section{Yeast}

$\mathrm{PSI+}$

PSI+ is the prionoid form of Sup35, a yeast protein subunit of a translation termination factor (Stansfield et al., 1996). PSI+ causes read through of stop codons in translating mRNAs. Although generally non-toxic to the cell, overproduction of the PSI+ conformation will lead to a decrease in health from loss-of-function. Heat shock proteins (HSPs) are chaperone proteins involved in the clearance of misfolded proteins and play a pivotal role in regulation of yeast prion-like proteins. Indeed, HSP104 can eliminate PSI+ when overproduced in yeast (Allen et al., 2006). HSP104 functions with the UPS, and when ubiquitin or critical elements of the UPS are knocked out in yeast, Sup35 converts to PSI+ at a higher frequency (Allen et al., 2006; Tank and True, 2009). Similarly, inhibiting autophagy promotes PSI+ production in yeast (Speldewinde et al., 2015). This effect may not involve direct ubiquitination of Sup35/PSI+, as ubiquitin-conjugated Sup35 was not found by multiple labs (Allen et al., 2006; Tank and True, 2009). Instead, the actinassociated protein Lsb2 is ubiquitinated and drives PSI+ formation (Chernova et al., 2017).

\section{$\mathrm{PIN}+$}

PIN+ is the prionoid form of Rnq1, a yeast polyQ protein of unknown function. PIN1+, sometimes referred to as $\mathrm{RNQ}+$, facilitates de novo formation of other yeast prionoids (Stein and True, 2011). Unlike Sup35, Rnq1 can be ubiquitinated endogenously (Allen et al., 2006). As with other yeast prion-like proteins, HSP104 is involved in eliminating misfolded PIN+ and ubiquitin ligases protect the cell from prion-like proteins produced by PIN1+ (Theodoraki et al., 2012; Yang et al., 2014). HSP 104 functions alongside the UPS, and when critical elements of the UPS are knocked out in yeast, Rnq1 converts to PIN1+ and forms amyloid-like fibrils (Allen et al., 2006; Yang et al., 2014).

\section{Conclusion}

SUMOylation and ubiquitination are common post-translational modifications which regulate protein function, interaction, trafficking, and structure. Often, SUMO and ubiquitin conjugation destines the substrate to the UPS for degradation. However, as discussed throughout this chapter, these moieties are multi-functional. The role of SUMOylation and ubiquitination in protein regulation is particularly interesting when amyloid and amyloid-like proteins are considered. A significant amount of energy is used in the conversion from a soluble to an amyloid fibrillar state, making the fibrillar state an unlikely resting state for the protein. Thus, it is intriguing as to how amyloids are produced. Post-translational modifications, in part, can trigger critical steps in the fibrillization process of amyloidogenic proteins.

This chapter investigates the role of SUMOylation and ubiquitination of amyloids in disease and health (Table 25.1). SUMOylation and ubiquitination of $\alpha$-synuclein, the amyloid involved in Parkinson's disease and other synucleinopathies, are likely independent processes. Generally, monoubiquitination of $\alpha$-synuclein promotes aggregation (Nonaka et al., 2005; Lee et al., 2008) while monoSUMOylation promotes solubility (Krumova et al., 2011) and polyubiquitination drives protein degradation via the UPS (Lee et al., 2009).

We then consider SOD1, TDP-43, and FUS amyloids involved in ALS. First, SOD1 has an interesting distinction between physiological and pathological SUMOylation patterns. Physiological SOD1 can be SUMO1-conjugated, whereas pathological SOD1 can be SUMOylated by SUMO1, SUMO2, or SUMO3. All SUMOylation appears to drive aggregation, but perhaps the increased capacity for SUMOylation of pathological SOD1 increases its likelihood of aggregation in a correlative manner. Second, TDP-43 pathogenicity is also influenced by SUMOylation. It is hypothesized that deSUMOylation may drive mutant TDP-43 to the cytosol where it is neurotoxic (Seyfried et al., 2010). Finally, although less well studied than SOD1 and TDP-43, toxic FUS is ubiquitinated in ALS.

This chapter then considers Alzheimer's disease and the amyloid components $\beta$-amyloid and tau. Overall, those suffering from Alzheimer's disease show a marked decrease in high molecular weight $(>75 \mathrm{kDa})$ SUMO2/3. We speculate, throughout this chapter, that changes in SUMO2/3 are likely 
Table 25.1 SUMOylation and ubiquitination of toxic amyloids. Summary of SUMOylation and ubiquitination of all toxic amyloids listed in this chapter

\begin{tabular}{|c|c|c|c|c|c|}
\hline Disease & Substrate & $\begin{array}{l}\text { SUMOlyation of } \\
\text { inclusion bodies }\end{array}$ & $\begin{array}{l}\text { Effect of SUMO on } \\
\text { neurodegeneration }\end{array}$ & $\begin{array}{l}\text { Ubiquitination of } \\
\text { inclusion bodies }\end{array}$ & $\begin{array}{l}\text { Effect of ubiquitin on } \\
\text { neurodegeneration }\end{array}$ \\
\hline \multirow{3}{*}{$\begin{array}{l}\text { Parkinson's } \\
\text { disease }\end{array}$} & a synuclein & SUMO1, SUMO2 & Unknown & Yes & Decreased \\
\hline & Parkin & SUMO1 & Unknown & Yes & Unknown \\
\hline & DJ-1 & SUMO1 & Unknown & Unknown & Unknown \\
\hline $\begin{array}{l}\text { Multiple systems } \\
\text { atrophy }\end{array}$ & a synuclein & SUMO1 & Unknown & Yes & Unknown \\
\hline $\begin{array}{l}\text { Dementia with } \\
\text { Lewy bodies }\end{array}$ & a synuclein & SUMO1 & Unknown & Yes & Unknown \\
\hline \multirow[t]{3}{*}{$\begin{array}{l}\text { Amyotrophic lateral } \\
\text { sclerosis }\end{array}$} & SOD1 & $\begin{array}{l}\text { SUMO1, } \\
\text { SUMO2/3 }\end{array}$ & Unknown & Unknown & Unknown \\
\hline & TDP-43 & SUMO2/3 & Unknown & Yes & Unknown \\
\hline & FUS & Unknown & Unknown & Yes & Unknown \\
\hline $\begin{array}{l}\text { Neuronal } \\
\text { intranuclear } \\
\text { inclusion disorder }\end{array}$ & Various & SUMO1 & Unknown & Yes & Unknown \\
\hline Ischaemia & Various & $\begin{array}{l}\text { SUMO1, } \\
\text { SUMO2/3 }\end{array}$ & Decreased & Unknown & Unknown \\
\hline \multirow[t]{2}{*}{$\begin{array}{l}\text { Alzheimer's } \\
\text { disease }\end{array}$} & $\begin{array}{l}\text { Amyloid b/ } \\
\text { APP }\end{array}$ & SUMO3 & Reduced & Unknown & Unknown \\
\hline & tau & SUMO3 & Increased & Yes & Unknown \\
\hline $\begin{array}{l}\text { Huntington's } \\
\text { disease }\end{array}$ & Huntingtin & SUMO1, SUMO2 & Increased & Yes & Decreased \\
\hline $\begin{array}{l}\text { Dentatorubral } \\
\text { Pallidoluysian } \\
\text { atrophy }\end{array}$ & Atrophin 1 & SUMO1 & Increased & Unknown & Unknown \\
\hline $\begin{array}{l}\text { Spinal and bulbar } \\
\text { muscular atrophy }\end{array}$ & $\begin{array}{l}\text { Androgen } \\
\text { receptor }\end{array}$ & SUMO1, SUMO3 & Unknown & Yes & Unknown \\
\hline $\begin{array}{l}\text { Spinocerebellar } \\
\text { ataxia }\end{array}$ & Ataxin & SUMO1 & Increased & Yes & Decreased \\
\hline Prion diseases & PrP & Unknown & Unknown & Yes & Decreased \\
\hline
\end{tabular}

alterations in the extent of polySUMOylation of the substrate. Therefore, we believe that polySUMOylation is decreased in Alzheimer's disease. Although speculative, the cause for decreased polySUMOylation is likely to come from its role in the UPS. PolySUMOylation can act as a marker for proteasomal degradation, functioning with downstream ubiquitination. In the case of Alzheimer's disease, we believe that high molecular weight SUMO2/3 is decreased because of polySUMO-targeting to the proteosome. Likely, polySUMOylation is an early stage phenomena, and decreases in late stage disease due to decreased proteasome integrity. Indeed, the decrease in high molecular weight SUMO2/3 is observed in early stages of Alzheimer's disease, and later stages of disease are marked by UPS dysfunction.
We further explore the role of SUMOylation and ubiquitination in Alzheimer's disease by considering the two amyloids involved, $\beta$-amyloid and tau. It appears that $\beta$-amyloid production is influenced by APP SUMOylation. In the case of tau, aggregation correlates with increased SUMOylation and degradation correlates with increased ubiquitination (Luo et al., 2014). As stated previously for general inclusion body formation, ubiquitination of the substrate drives the toxic protein to degradation. However, if toxic proteins overwhelm the system, ubiquitinated proteins may be left in inclusion bodies as a final attempt to regulate pathogenicity. We further hypothesize about the role of SUMOylation on tau fibrillization. We offer that SUMOylation of unbound tau may be the critical structural point that converts tau to an amyloid, 
allowing for downstream hyperphosphorylation and fibrillization.

SUMOylation and ubiquitination of polyglutamine diseases are then considered. First, we investigate Huntington's disease amyloid, Htt. Generally, SUMOylation of Htt leads to increased aggregation and ubiquitination of $\mathrm{Htt}$ leads to increased solubility. An important distinction arises when the SUMO protein being conjugated to $\mathrm{Htt}$ differs. SUMO2 appears to be the key driving force behind $\mathrm{Htt}$ aggregation. Both monoSUMOylation and polySUMOylation are neurotoxic, but we hypothesize that polySUMOylation plays a protective role. Research suggests that only soluble polyQ proteins are able to be degraded through proteasomal mechanisms (Verhoef et al., 2002; Kaytor et al., 2004; Michalik and Van Broeckhoven, 2004; Juenemann et al., 2013). However, the cell still needs to control toxic polyQ production in some way. Likely, polySUMOylation drives $\mathrm{Htt}$ into inclusion bodies.

Let's assume that polySUMOylation controls non-degradable polyQ proteins by driving inclusion body formation. We hypothesize that soluble polyQ proteins are ubiquitinated and degraded via the UPS. Insoluble polyQ proteins are incapable of being degraded via the UPS. Therefore, insoluble polyQ proteins are instead SUMOylated. This then allows the available lysine residues to be mono- or poly-SUMOylated.

Not all polyQ proteins behave similarly to Htt. Both SUMO- and ubiquitin-conjugation to androgen receptor keep the protein soluble and monomeric (Mukherjee et al., 2009) in DRPLA. Furthermore, in SCA, SUMO1-conjugation promotes protein insolubility and neurotoxicity. In SCA-I, data suggests SUMO2/3- or ubiquitinconjugation inhibits disease progression, possibly via UPS-driven degradation. This again strengthens our hypothesis that polySUMOylation allows some amyloidogenic proteins to work via the UPS towards degradation or inclusion body formation.

Our penultimate investigation into toxic amyloids considers NIID. NIID lacks a specific protein which drives pathology; instead, many of the polyQ proteins previously discussed are within the inclusions which hallmark the disease. These inclusions likely arise from a general misregulation of SUMOand ubiquitination.

Finally, we consider prion diseases and the roles SUMOylation and ubiquitination play in regulating the amyloidogenic protein. We speculate that polySUMOylation is negatively impacted in prion diseases. This would also lead to a decrease in PrPsc targeting to the proteasome, which is already severely impaired.

After considering the wealth of knowledge on toxic amyloids, we investigate the more recent literature on functional amyloids in mammals and yeast. RNA-binding protein CPEB3 is likely regulated by a SUMO-ubiquitin switch, driving translation functionality. The data indicates that SUMOylation of CPEB3 produces an inhibitory function, and ubiquitination of the protein promotes translation activity. Another RNA-binding protein, La, also switches functions based on if the protein is SUMOylated or deSUMOylated. Finally, MAVS is an excellent example of functional ubiquitination. Ubiquitination of MAVS allows for the conformational change to a fibrillar structure, with downstream functional effects.

Finally, we end our investigation with yeast functional amyloids. Thus far, yeast have been the most prevalent model organism used in functional amyloid studies. From this work, numerous yeast prion-like proteins have been discovered. Here, we consider PSI+ and PIN1+. There is a wealth of information suggesting that the UPS is disrupted when either of these yeast prionoids are expressed.

Overall, we can draw numerous conclusions. First, and most importantly, there is no generic function for SUMOylation or ubiquitination of amyloids. Each protein is distinct and will be impacted by PTMs differently; this is true even within protein families, as identified in the SCA section. Second, the data suggests that inclusion bodies act as a 'dumping ground' in disease. Often, the UPS is unable to perform its function or is overwhelmed with misfolded proteins in amyloid diseases. The inclusion bodies offer a final attempt to compartmentalize toxic species. Third, we hypothesize that polySUMOylation plays an important role in many of the above mentioned diseases. Likely, polySUMOylation is a second method in which the cell can target toxic species for degradation or inclusion body formation. The functional amyloid section provides important examples of the complexity of PTMs, and the resulting downstream effects.

One outstanding difficulty in the field is deciphering which SUMOylation and ubiquitination patterns are part of protein function, and which 
patterns are part of cellular stress resulting from pathology. Furthermore, PTMs are highly dynamic, altering as the cell requires. Complexity is increased when crosstalk is considered. We briefly mentioned the influence of tau SUMOylation on downstream hyperphosphorylation. Many more examples of PTM crosstalk are known for these proteins but were not covered. In order to fully understand the role SUMOylation, ubiquitination, and other PTMs play on amyloids in health and disease, then state of health, time of quantification, and extent of crosstalk all must be understood.

Although a large task, quantitative proteomics allows for a deeper understanding of the role of PTMs on amyloid function. Soon, more methodological advancements will allow us to probe deeper and ask more complex questions. We are excited to see the field progress our understanding of cellular regulation of amyloids in health and disease, and to gain insight into the roles PTMs play in the cellular regulation of amyloids in the brain.

\section{Acknowledgements}

We would like to thank Joe Rayman and Pauline Henick for their comments on content and editing.

\section{References}

Aguzzi, A., Heikenwalder, M., and Polymenidou, M. (2007). Insights into prion strains and neurotoxicity. Nat. Rev. Mol. Cell Biol. 8, 552-561.

Allen, C., Büttner, S., Aragon, A.D., Thomas, J.A., Meirelles, O., Jaetao, J.E., Benn, D., Ruby, S.W., Veenhuis, M., Madeo, F., et al. (2006). Isolation of quiescent and nonquiescent cells from yeast stationary-phase cultures. J. Cell Biol. 174, 89-100.

Almeida, B., Abreu, I.A., Matos, C.A., Fraga, J.S., Fernandes, S., Macedo, M.G., Gutiérrez-Gallego, R., Pereira, P.J., Carvalho, A.L., and Macedo-Ribeiro, S. (2015). SUMOylation of the brain-predominant Ataxin-3 isoform modulates its interaction with p97. Biochim. Biophys. Acta 1852, 1950-1959. https://doi. org/10.1016/j.bbadis.2015.06.010.

Al-Ramahi, I., Lam, Y.C., Chen, H.K., de Gouyon, B., Zhang, M., Pérez, A.M., Branco, J., de Haro, M., Patterson, C., Zoghbi, H.Y., et al. (2006). CHIP protects from the neurotoxicity of expanded and wild-type ataxin-1 and promotes their ubiquitination and degradation. J. Biol. Chem. 281, 26714-26724.

Andersen, P.M. (2006). Amyotrophic lateral sclerosis associated with mutations in the $\mathrm{CuZn}$ superoxide dismutase gene. Curr. Neurol. Neurosci. Rep. 6, 37-46.

Arai, T., Hasegawa, M., Akiyama, H., Ikeda, K., Nonaka, T., Mori, H., Mann, D., Tsuchiya, K., Yoshida, M., Hashizume, Y., et al. (2006). TDP-43 is a component of ubiquitin-positive tau-negative inclusions in frontotemporal lobar degeneration and amyotrophic lateral sclerosis. Biochem. Biophys. Res. Commun. 351, 602-611.

Arrasate, M., Mitra, S., Schweitzer, E.S., Segal, M.R., and Finkbeiner, S. (2004). Inclusion body formation reduces levels of mutant huntingtin and the risk of neuronal death. Nature 431, 805-810.

Banci, L., Bertini, I., Boca, M., Calderone, V., Cantini, F., Girotto, S., and Vieru, M. (2009). Structural and dynamic aspects related to oligomerization of apo SOD 1 and its mutants. Proc. Natl. Acad. Sci. U.S.A. 106, 69806985. https://doi.org/10.1073/pnas.0809845106.

Baumketner, A., Bernstein, S.L., Wyttenbach, T., Bitan, G., Teplow, D.B., Bowers, M.T., and Shea, J.E. (2006). Amyloid beta-protein monomer structure: a computational and experimental study. Protein Sci. 15, 420-428.

Bence, N.F., Sampat, R.M., and Kopito, R.R. (2001). Impairment of the ubiquitin-proteasome system by protein aggregation. Science 292, 1552-1555. https:// doi.org/10.1126/science.292.5521.1552.

Bennett, E.J., Bence, N.F., Jayakumar, R., and Kopito, R.R. (2005). Global impairment of the ubiquitin-proteasome system by nuclear or cytoplasmic protein aggregates precedes inclusion body formation. Mol. Cell 17, 351-365.

Bertram, L., Hiltunen, M., Parkinson, M., Ingelsson, M., Lange, C., Ramasamy, K., Mullin, K., Menon, R., Sampson, A.J., Hsiao, M.Y., et al. (2005). Family-based association between Alzheimer's disease and variants in UBQLN1. N. Engl. J. Med. 352, 884-894. https://doi. org/10.1056/NEJMoa042765.

Besnault-Mascard, L., Leprince, C., Auffredou, M.T., Meunier, B., Bourgeade, M.F., Camonis, J., Lorenzo, H.K., and Vazquez, A. (2005). Caspase-8 sumoylation is associated with nuclear localization. Oncogene 24, 3268-3273.

Blennow, K., de Leon, M.J., and Zetterberg, H. (2006). Alzheimer's disease. Lancet 368, 387-403. https://doi. org/10.1016/S0140-6736(06)69113-7.

Bohren, K.M., Nadkarni, V., Song, J.H., Gabbay, K.H., and Owerbach, D. (2004). A M55V polymorphism in a novel SUMO gene (SUMO-4) differentially activates heat shock transcription factors and is associated with susceptibility to type I diabetes mellitus. J. Biol. Chem. 279, 27233-27238. https://doi.org/10.1074/jbc. M402273200.

Bolton, D.C., McKinley, M.P., and Prusiner, S.B. (1982). Identification of a protein that purifies with the scrapie prion. Science 218, 1309-1311.

Braak, H., Braak, E., Yilmazer, D., de Vos, R.A., Jansen, E.N., and Bohl, J. (1996). Pattern of brain destruction in Parkinson's and Alzheimer's diseases. J. Neural Transm. 103, 455-490.

Braak, H., Rub, U., Gai, W.P., and Del Tredici, K. (2003). Idiopathic Parkinson's disease: possible routes by which vulnerable neuronal types may be subject to neuroinvasion by an unknown pathogen. J. Neural Transm. (Vienna) 110, 517-536. https://doi. org/10.1007/s00702-002-0808-2.

Bruijn, L.I., Houseweart, M.K., Kato, S., Anderson, K.L., Anderson, S.D., Ohama, E., Reaume, A.G., Scott, 
R.W., and Cleveland, D.W. (1998). Aggregation and motor neuron toxicity of an ALS-linked SOD1 mutant independent from wild-type SOD1. Science 281, 1851-1854.

Buratti, E., Dörk, T., Zuccato, E., Pagani, F., Romano, M., and Baralle, F.E. (2001). Nuclear factor TDP-43 and SR proteins promote in vitro and in vivo CFTR exon 9 skipping. EMBO J. 20, 1774-1784. https://doi. org/10.1093/emboj/20.7.1774.

Burnett, B., Li, F., and Pittman, R.N. (2003). The polyglutamine neurodegenerative protein ataxin-3 binds polyubiquitylated proteins and has ubiquitin protease activity. Hum. Mol. Genet. 12, 3195-3205. https://doi. org/10.1093/hmg/ddg344.

Cairns, N.J., Neumann, M., Bigio, E.H., Holm, I.E., Troost, D., Hatanpaa, K.J., Foong, C., White, C.L., Schneider, J.A., Kretzschmar, H.A., et al. (2007). TDP-43 in familial and sporadic frontotemporal lobar degeneration with ubiquitin inclusions. Am. J. Pathol. 171, 227-240.

Cardozo, C., and Michaud, C. (2002). Proteasome-mediated degradation of tau proteins occurs independently of the chymotrypsin-like activity by a nonprocessive pathway. Arch. Biochem. Biophys. 408, 103-110.

Castanier, C., Zemirli, N., Portier, A., Garcin, D., Bidère, N., Vazquez, A., and Arnoult, D. (2012). MAVS ubiquitination by the E3 ligase TRIM25 and degradation by the proteasome is involved in type I interferon production after activation of the antiviral RIG-I-like receptors. BMC Biol. 10, 44. https://doi. org/10.1186/1741-7007-10-44.

Cattaneo, E., Rigamonti, D., Goffredo, D., Zuccato, C., Squitieri, F., and Sipione, S.(2001). Loss of normal huntingtin function: new developments in Huntington's disease research. Trends Neurosci. 24, 182-188.

Chan, H.Y., Warrick, J.M., Andriola, I., Merry, D., and Bonini, N.M. (2002). Genetic modulation of polyglutamine toxicity by protein conjugation pathways in Drosophila. Hum. Mol. Genet. 11, 2895-2904.

Chandra, S., Fornai, F., Kwon, H.B., Yazdani, U., Atasoy, D., Liu, X., Hammer, R.E., Battaglia, G., German, D.C., Castillo, P.E., et al. (2004). Double-knockout mice for alpha- and beta-synucleins: effect on synaptic functions. Proc. Natl. Acad. Sci. U.S.A. 101, 14966-14971.

Chandra, S., Gallardo, G., Fernandez-Chacon, R., Schluter, O.M., and Sudhof, T.C. (2005). alphasynuclein cooperates with CSP alpha in preventing neurodegeneration. Cell 123, 383-396. https://doi. org/10.1016/j.cell.2005.09.028.

Chen, L., Thiruchelvam, M.J., Madura, K., and Richfield, E.K. (2006). Proteasome dysfunction in aged human alpha-synuclein transgenic mice. Neurobiol. Dis. 23, $120-126$.

Chen, Z.J., and Sun, L.J. (2009). Nonproteolytic functions of ubiquitin in cell signaling. Mol. Cell 33, 275-286. https://doi.org/10.1016/j.molcel.2009.01.014.

Cheng, C.H., Lo, Y.H., Liang, S.S., Ti, S.C., Lin, F.M., Yeh, C.H., Huang, H.Y., and Wang, T.F. (2006). SUMO modifications control assembly of synaptonemal complex and polycomplex in meiosis of Saccharomyces cerevisiae. Genes Dev. 20, 2067-2081.

Chernova, T.A., Allen, K.D., Wesoloski, L.M., Shanks, J.R., Chernoff, Y.O., and Wilkinson, K.D. (2003). Pleiotropic effects of Ubp6 loss on drug sensitivities and yeast prion are due to depletion of the free ubiquitin pool. J. Biol. Chem. 278, 52102-52115. https://doi.org/10.1074/ jbc.M310283200.

Cheroni, C., Marino, M., Tortarolo, M., Veglianese, P., De Biasi, S., Fontana, E., Zuccarello, L.V., Maynard, C.J., Dantuma, N.P., and Bendotti, C. (2009). Functional alterations of the ubiquitin-proteasome system in motor neurons of a mouse model of familial amyotrophic lateral sclerosis dagger. Hum. Mol. Genet. 18, 82-96. https:// doi.org/10.1093/hmg/ddn319.

Chiti, F., and Dobson, C.M. (2006). Protein misfolding, functional amyloid, and human disease. Annu. Rev. Biochem. 75, 333-366. https://doi.org/10.1146/ annurev.biochem.75.101304.123901.

Clague, M.J., Barsukov, I., Coulson, J.M., Liu, H., Rigden, D.J., and Urbé, S. (2013). Deubiquitylases from genes to organism. Physiol. Rev. 93, 1289-1315. https://doi. org/10.1152/physrev.00002.2013.

Clague, M.J., Heride, C., and Urbé, S. (2015). The demographics of the ubiquitin system. Trends Cell Biol. 25, 417-426. https://doi.org/10.1016/j. tcb.2015.03.002.

Clavaguera, F., Bolmont, T., Crowther, R.A., Abramowski, D., Frank, S., Probst, A., Fraser, G., Stalder, A.K., Beibel, M., Staufenbiel, M., et al. (2009). Transmission and spreading of tauopathy in transgenic mouse brain. Nat. Cell Biol. 11, 909-913. https://doi.org/10.1038/ ncb1901.

Conway, K.A., Harper, J.D., and Lansbury, P.T. (2000). Fibrils formed in vitro from alpha-synuclein and two mutant forms linked to Parkinson's disease are typical amyloid. Biochemistry 39, 2552-2563.

Corneveaux, J.J., Myers, A.J., Allen, A.N., Pruzin, J.J., Ramirez, M., Engel, A., Nalls, M.A., Chen, K., Lee, W., Chewning, K., et al. (2010). Association of CR1, CLU and PICALM with Alzheimer's disease in a cohort of clinically characterized and neuropathologically verified individuals. Hum. Mol. Genet. 19, 3295-3301. https:// doi.org/10.1093/hmg/ddq221.

Corsetti, V., Florenzano, F., Atlante, A., Bobba, A., Ciotti, M.T., Natale, F., Della Valle, F., Borreca, A., Manca, A., Meli, G., et al. (2015). NH2-truncated human tau induces deregulated mitophagy in neurons by aberrant recruitment of Parkin and UCHL-1: implications in Alzheimer's disease. Hum. Mol. Genet. 24, 3058-3081. https://doi.org/ 10.1093/hmg/ddv059.

Crescenzi, O., Tomaselli, S., Guerrini, R., Salvadori, S., D’Ursi, A.M., Temussi, P.A., and Picone, D. (2002). Solution structure of the Alzheimer amyloid betapeptide (1-42) in an apolar microenvironment. Similarity with a virus fusion domain. Eur. J. Biochem. 269, 5642-5648.

Cripps, D., Thomas, S.N., Jeng, Y., Yang, F., Davies, P., and Yang, A.J. (2006). Alzheimer disease-specific conformation of hyperphosphorylated paired helical filament-Tau is polyubiquitinated through Lys-48, Lys11, and Lys-6 ubiquitin conjugation. J. Biol. Chem. 281, $10825-10838$.

Cummings, C.J., and Zoghbi, H.Y. (2000). Fourteen and counting: unraveling trinucleotide repeat diseases. Hum. Mol. Genet. 9, 909-916.

Cummings, C.J., Reinstein, E., Sun, Y., Antalffy, B., Jiang, Y., Ciechanover, A., Orr, H.T., Beaudet, A.L., and Zoghbi, 
H.Y. (1999). Mutation of the E6-AP ubiquitin ligase reduces nuclear inclusion frequency while accelerating polyglutamine-induced pathology in SCA1 mice. Neuron 24, 879-892.

David, D.C., Layfield, R., Serpell, L., Narain, Y., Goedert, M., and Spillantini, M.G. (2002). Proteasomal degradation of tau protein. J. Neurochem. 83, 176-185.

Davies, S.W., Turmaine, M., Cozens, B.A., DiFiglia, M., Sharp, A.H., Ross, C.A., Scherzinger, E., Wanker, E.E., Mangiarini, L., and Bates, G.P. (1997). Formation of neuronal intranuclear inclusions underlies the neurological dysfunction in mice transgenic for the HD mutation. Cell 90, 537-548.

Deng, H.X., Zhai, H., Bigio, E.H., Yan, J., Fecto, F., Ajroud, K., Mishra, M., Ajroud-Driss, S., Heller, S., Sufit, R., et al. (2010). FUS-immunoreactive inclusions are a common feature in sporadic and non-SOD1 familial amyotrophic lateral sclerosis. Ann. Neurol. 67, 739-748. https://doi. org/10.1002/ana.22051.

Denison, C., Rudner, A.D., Gerber, S.A., Bakalarski, C.E., Moazed, D., and Gygi, S.P. (2005). A proteomic strategy for gaining insights into protein sumoylation in yeast. Mol. Cell Proteomics 4, 246-254.

Deriziotis, P., André, R., Smith, D.M., Goold, R., Kinghorn, K.J., Kristiansen, M., Nathan, J.A., Rosenzweig, R., Krutauz, D., Glickman, M.H., et al. (2011). Misfolded PrP impairs the UPS by interaction with the $20 \mathrm{~S}$ proteasome and inhibition of substrate entry. EMBO J. 30, 3065-3077. https://doi.org/10.1038/ emboj.2011.224.

Deshaies, R.J., and Joazeiro, C.A. (2009). RING domain E3 ubiquitin ligases. Annu. Rev. Biochem. 78, 399-434. https://doi.org/10.1146/annurev. biochem.78.101807.093809.

Desterro, J.M., Thomson, J., and Hay, R.T. (1997). Ubch9 conjugates SUMO but not ubiquitin. FEBS Lett. 417, 297-300.

Dewey, C.M., Cenik, B., Sephton, C.F., Johnson, B.A., Herz, J., and Yu, G. (2012). TDP-43 aggregation in neurodegeneration: are stress granules the key? Brain Res. 1462, 16-25. https://doi.org/10.1016/j. brainres.2012.02.032.

Dickson, D.W., Liu, W., Hardy, J., Farrer, M., Mehta, N., Uitti, R., Mark, M., Zimmerman, T., Golbe, L., Sage, J., et al. (1999). Widespread alterations of alpha-synuclein in multiple system atrophy. Am. J. Pathol. 155, 1241-1251.

Dobson, C.M. (2003). Protein folding and misfolding. Nature 426, 884-890. https://doi.org/10.1038/ nature 02261 .

Dormann, D., and Haass, C. (2011). TDP-43 and FUS: a nuclear affair. Trends Neurosci. 34, 339-348. https:// doi.org/10.1016/j.tins.2011.05.002.

Dorval, V., and Fraser, P.E. (2006). Small ubiquitin-like modifier (SUMO) modification of natively unfolded proteins tau and alpha-synuclein. J. Biol. Chem. 281, 9919-9924.

Dorval, V., Mazzella, M.J., Mathews, P.M., Hay, R.T., and Fraser, P.E. (2007). Modulation of Abeta generation by small ubiquitin-like modifiers does not require conjugation to target proteins. Biochem. J. 404, 309-316.

Drisaldi, B., Colnaghi, L., Fioriti, L., Rao, N., Myers, C., Snyder, A.M., Metzger, D.J., Tarasoff, J., Konstantinov, E., Fraser, P.E., et al. (2015). SUMOylation is an inhibitory constraint that regulates the prion-like aggregation and activity of CPEB3. Cell Rep. 11, 1694-1702. https:// doi.org/10.1016/j.celrep.2015.04.061.

Drummond, E., Nayak, S., Pires, G., Ueberheide, B., and Wisniewski, T. (2018). Isolation of amyloid plaques and neurofibrillary tangles from archived Alzheimer's disease tissue using laser-capture microdissection for downstream proteomics. Methods Mol. Biol. 1723, 319-334. https://doi.org/10.1007/978-1-4939-75587_18.

Dyer, R.B., and McMurray, C.T. (2001). Mutant protein in Huntington disease is resistant to proteolysis in affected brain. Nat. Genet. 29, 270-278. https://doi. org/10.1038/ng745.

Ehrnhoefer, D.E., Sutton, L., and Hayden, M.R. (2011). Small changes, big impact: posttranslational modifications and function of huntingtin in Huntington disease. Neuroscientist 17, 475-492. https://doi. org/10.1177/1073858410390378.

Eisele, Y.S., Obermüller, U., Heilbronner, G., Baumann, F., Kaeser, S.A., Wolburg, H., Walker, L.C., Staufenbiel, M., Heikenwalder, M., and Jucker, M. (2010). Peripherally applied a beta-containing inoculates induce cerebral beta-amyloidosis. Science 330, 980-982. https://doi. org/10.1126/science.1194516.

Elam, J.S., Taylor, A.B., Strange, R., Antonyuk, S., Doucette, P.A., Rodriguez, J.A., Hasnain, S.S., Hayward, L.J., Valentine, J.S., Yeates, T.O., et al. (2003). Amyloid-like filaments and water-filled nanotubes formed by SOD1 mutant proteins linked to familial ALS. Nat. Struct. Biol. 10, 461-467. https://doi.org/10.1038/nsb935.

El Ayadi, A., Stieren, E.S., Barral, J.M., and Boehning, D. (2012). Ubiquilin-1 regulates amyloid precursor protein maturation and degradation by stimulating K63-linked polyubiquitination of lysine 688. Proc. Natl. Acad. Sci. U.S.A. 109, 13416-13421. https://doi.org/10.1073/ pnas. 1206786109.

Farrawell, N.E., Lambert-Smith, I.A., Warraich, S.T., Blair, I.P., Saunders, D.N., Hatters, D.M., and Yerbury, J.J. (2015). Distinct partitioning of ALS associated TDP43, FUS and SOD1 mutants into cellular inclusions. Sci. Rep. 5, 13416. https://doi.org/10.1038/srep13416.

Fei, E., Jia, N., Yan, M., Ying, Z., Sun, Q. Wang, H., Zhang, T., Ma, X., Ding, H., Yao, X., et al. (2006). SUMO-1 modification increases human SOD1 stability and aggregation. Biochem. Biophys. Res. Commun. 347, 406-412.

Feligioni, M., Marcelli, S., Knock, E., Nadeem, U., Arancio, O., and Fraser, P.E. (2015). SUMO modulation of protein aggregation and degradation. Aims Mol. Sci. 2, $382-410$.

Fernandez-Funez, P., Nino-Rosales, M.L., de Gouyon, B., She, W.C., Luchak, J.M., Martinez, P., Turiegano, E., Benito, J., Capovilla, M., Skinner, P.J., et al. (2000). Identification of genes that modify ataxin-1-induced neurodegeneration. Nature 408, 101-106. https://doi. org/10.1038/35040584.

Finley, D. (2009). Recognition and processing of ubiquitinprotein conjugates by the proteasome. Annu. Rev. Biochem. 78, 477-513. https://doi.org/10.1146/ annurev.biochem.78.081507.101607.

Fioriti, L., Myers, C., Huang, Y.Y., Li, X., Stephan, J.S., Trifilieff, P., Colnaghi, L., Kosmidis, S., Drisaldi, 
B., Pavlopoulos, E., et al. (2015). The persistence of hippocampal-based memory requires protein synthesis mediated by the prion-like protein CPEB3. Neuron 86, 1433-1448. https://doi.org/10.1016/j. neuron.2015.05.021.

Fitzpatrick, A.W.P., Falcon, B., He, S., Murzin, A.G., Murshudov, G., Garringer, H.J., Crowther, R.A., Ghetti, B., Goedert, M., and Scheres, S.H.W. (2017). Cryo-EM structures of tau filaments from Alzheimer's disease. Nature 547, 185-190. https://doi.org/10.1038/ nature23002.

Ford, L., Ling, E., Kandel, E.R., and Fioriti, L. (2019). CPEB3 inhibits translation of mRNA targets by localizing them to P bodies. Proc. Natl. Acad. Sci. U.S.A. In review.

Forman, M.S., Trojanowski, J.Q., and Lee, V.M. (2007). TDP-43: a novel neurodegenerative proteinopathy. Curr. Opin. Neurobiol. 17, 548-555.

Frost, B., and Diamond, M.I. (2010). Prion-like mechanisms in neurodegenerative diseases. Nat. Rev. Neurosci. 11, 155-159. https://doi.org/10.1038/nrn2786.

García-Mata, R., Bebök, Z., Sorscher, E.J., and Sztul, E.S. (1999). Characterization and dynamics of aggresome formation by a cytosolic GFP-chimera. J. Cell Biol. 146, 1239-1254.

Gatchel, J.R., and Zoghbi, H.Y. (2005). Diseases of unstable repeat expansion: mechanisms and common principles. Nat. Rev. Genet. 6, 743-755.

Geiss-Friedlander, R., and Melchior, F. (2007). Concepts in sumoylation: a decade on. Nat. Rev. Mol. Cell Biol. 8, 947-956.

Gibbs, C.J., Gajdusek, D.C., Asher, D.M., Alpers, M.P., Beck, E., Daniel, P.M., and Matthews, W.B. (1968). CreutzfeldtJakob disease (spongiform encephalopathy): transmission to the chimpanzee. Science 161, 388-389.

Gocke, C.B., Yu, H., and Kang, J. (2005). Systematic identification and analysis of mammalian small ubiquitin-like modifier substrates. J. Biol. Chem. 280, 5004-5012.

Goedert,M.(2001).Alpha-synuclein and neurodegenerative diseases. Nat. Rev. Neurosci. 2, 492-501. https://doi. org/10.1038/35081564.

Goedert, M., and Spillantini, M.G. (2006). A century of Alzheimer's disease. Science 314, 777-781.

Gong, L., Li, B., Millas, S., and Yeh, E.T. (1999). Molecular cloning and characterization of human AOS1 and UBA2, components of the sentrin-activating enzyme complex. FEBS Lett. 448, 185-189.

Graham, J.G., and Oppenheimer, D.R. (1969). Orthostatic hypotension and nicotine sensitivity in a case of multiple system atrophy. J. Neurol. Neurosurg. Psychiatry 32, 28-34.

Greenfield, J.P., Tsai, J., Gouras, G.K., Hai, B., Thinakaran, G., Checler, F., Sisodia, S.S., Greengard, P., and Xu, H. (1999). Endoplasmic reticulum and trans-Golgi network generate distinct populations of Alzheimer beta-amyloid peptides. Proc. Natl. Acad. Sci. U.S.A. 96, $742-747$.

Grupe, A., Abraham, R., Li, Y., Rowland, C., Hollingworth, P., Morgan, A., Jehu, L., Segurado, R., Stone, D., Schadt, E., et al. (2007). Evidence for novel susceptibility genes for late-onset Alzheimer's disease from a genome-wide association study of putative functional variants. Hum. Mol. Genet. 16, 865-873.

Guerrero-Ferreira, R., Taylor, N.M., Mona, D., Ringler, P., Lauer, M.E., Riek, R., Britschgi, M., and Stahlberg, H. (2018). Cryo-EM structure of alpha-synuclein fibrils. Elife 7, e36402. https://doi.org/10.7554/eLife.36402.

Guo, D., Li, M., Zhang, Y., Yang, P., Eckenrode, S., Hopkins, D., Zheng, W., Purohit, S., Podolsky, R.H., Muir, A., et al. (2004). A functional variant of SUMO4, a new I kappa $\mathrm{B}$ alpha modifier, is associated with type 1 diabetes. Nat. Genet. 36, 837-841. https://doi.org/10.1038/ng1391.

Guo, J.L., and Lee, V.M. (2011). Seeding of normal Tau by pathological Tau conformers drives pathogenesis of Alzheimer-like tangles. J. Biol. Chem. 286, 1531715331. https://doi.org/10.1074/jbc.M110.209296.

Guo, L., Giasson, B.I., Glavis-Bloom, A., Brewer, M.D., Shorter, J., Gitler, A.D., and Yang, X. (2014). A cellular system that degrades misfolded proteins and protects against neurodegeneration. Mol. Cell 55, 15-30. https://doi.org/10.1016/j.molcel.2014.04.030.

Hao, R., Nanduri, P., Rao, Y., Panichelli, R.S., Ito, A., Yoshida, M., and Yao, T.P. (2013). Proteasomes activate aggresome disassembly and clearance by producing unanchored ubiquitin chains. Mol. Cell 51, 819-828. https://doi.org/10.1016/j.molcel.2013.08.016.

Hay, R.T. (2005). SUMO: a history of modification. Mol. Cell 18,1-12.

Hayashi, N., Shirakura, H., Uehara, T., and Nomura, Y. (2006). Relationship between SUMO-1 modification of caspase-7 and its nuclear localization in human neuronal cells. Neurosci. Lett. 397, 5-9.

Hayashi, T., Seki, M., Maeda, D., Wang, W., Kawabe, Y., Seki, T., Saitoh, H., Fukagawa, T., Yagi, H., and Enomoto, T. (2002). Ubc9 is essential for viability of higher eukaryotic cells. Exp. Cell Res. 280, 212-221.

Hershko, A., and Ciechanover, A. (1998). The ubiquitin system. Ann. Rev. Biochem. 67, 425-479. https://doi. org/10.1146/annurev.biochem.67.1.425.

Holmberg, C.I., Staniszewski, K.E., Mensah, K.N., Matouschek, A., and Morimoto, R.I. (2004). Inefficient degradation of truncated polyglutamine proteins by the proteasome. EMBO J. 23, 4307-4318.

Homma, T., Ishibashi, D., Nakagaki, T., Fuse, T., Mori, T., Satoh, K., Atarashi, R., and Nishida, N. (2015). Ubiquitin-specific protease 14 modulates degradation of cellular prion protein. Sci. Rep. 5, 11028. https://doi. org/10.1038/srep11028.

Hou, F., Sun, L., Zheng, H., Skaug, B., Jiang, Q.X., and Chen, Z.J. (2011). MAVS forms functional prion-like aggregates to activate and propagate antiviral innate immune response. Cell 146, 448-461. https://doi. org/10.1016/j.cell.2011.06.041.

Howland, D.S., Liu, J., She, Y., Goad, B., Maragakis, N.J., Kim, B., Erickson, J., Kulik, J., DeVito, L., Psaltis, G., et al. (2002). Focal loss of the glutamate transporter EAAT2 in a transgenic rat model of SOD1 mutant-mediated amyotrophic lateral sclerosis (ALS). Proc. Natl. Acad. Sci. U.S.A. 99, 1604-1609. https://doi.org/10.1073/ pnas.032539299.

Ichimura, Y., Kirisako, T., Takao, T., Satomi, Y., Shimonishi, Y., Ishihara, N., Mizushima, N., Tanida, I., Kominami, E., Ohsumi, M., et al. (2000). A ubiquitin-like system 
mediates protein lipidation. Nature 408, 488-492. https://doi.org/10.1038/35044114.

Iwata, A., Maruyama, M., Kanazawa, I., and Nukina, N. (2001). alpha-Synuclein affects the MAPK pathway and accelerates cell death. J. Biol. Chem. 276, 45320-45329. https://doi.org/10.1074/jbc.M103736200.

Jana, N.R., Zemskov, E.A., Wang, G.H., and Nukina, N. (2001). Altered proteasomal function due to the expression of polyglutamine-expanded truncated $\mathrm{N}$-terminal huntingtin induces apoptosis by caspase activation through mitochondrial cytochrome c release. Hum. Mol. Genet. 10, 1049-1059. https://doi. org/10.1093/hmg/10.10.1049.

Janer, A., Werner, A., Takahashi-Fujigasaki, J., Daret, A., Fujigasaki, H., Takada, K., Duyckaerts, C., Brice, A., Dejean, A., and Sittler, A. (2010). SUMOylation attenuates the aggregation propensity and cellular toxicity of the polyglutamine expanded ataxin-7. Hum. Mol. Genet. 19, 181-195. https://doi.org/10.1093/ $\mathrm{hmg} / \mathrm{ddp} 478$.

Johnson, B.S., McCaffery, J.M., Lindquist, S., and Gitler, A.D. (2008). A yeast TDP-43 proteinopathy model: Exploring the molecular determinants of TDP-43 aggregation and cellular toxicity. Proc. Natl. Acad. Sci. U.S.A. 105, 6439-6444. https://doi.org/10.1073/ pnas.0802082105.

Johnston, J.A., Ward, C.L., and Kopito, R.R. (1998). Aggresomes: a cellular response to misfolded proteins. J. Cell Biol. 143, 1883-1898.

Juenemann, K., Schipper-Krom, S., Wiemhoefer, A., Kloss, A., Sanz Sanz, A., and Reits, E.A. (2013). Expanded polyglutamine-containing $\mathrm{N}$-terminal huntingtin fragments are entirely degraded by mammalian proteasomes. J. Biol. Chem. 288, 27068-27084. https:// doi.org/10.1074/jbc.M113.486076.

Kabashi, E., Valdmanis, P.N., Dion, P., Spiegelman, D., McConkey, B.J., Vande Velde, C., Bouchard, J.P., Lacomblez, L., Pochigaeva, K., Salachas, F., et al. (2008). TARDBP mutations in individuals with sporadic and familial amyotrophic lateral sclerosis. Nat. Genet. 40, 572-574. https://doi.org/10.1038/ng.132.

Kalchman, M.A., Graham, R.K., Xia, G., Koide, H.B., Hodgson, J.G., Graham, K.C., Goldberg, Y.P., Gietz, R.D., Pickart, C.M., and Hayden, M.R. (1996). Huntingtin is ubiquitinated and interacts with a specific ubiquitinconjugating enzyme. J. Biol. Chem. 271, 19385-19394.

Kaminsky, Y.G., Marlatt, M.W., Smith, M.A., and Kosenko, E.A. (2010). Subcellular and metabolic examination of amyloid-beta peptides in Alzheimer disease pathogenesis: evidence for Abeta(25-35). Exp. Neurol. 221, 26-37. https://doi.org/10.1016/j. expneurol.2009.09.005.

Kamitani, T., Kito, K., Nguyen, H.P., and Yeh, E.T. (1997). Characterization of NEDD8, a developmentally downregulated ubiquitin-like protein. J. Biol. Chem. 272, 28557-28562.

Kang, S.C., Brown, D.R., Whiteman, M., Li, R., Pan, T., Perry, G., Wisniewski, T., Sy, M.S., and Wong, B.S. (2004). Prion protein is ubiquitinated after developing protease resistance in the brains of scrapie-infected mice. J. Pathol. 203, 603-608. https://doi.org/10.1002/ path.1555.
Karu, T.I., Pyatibrat, L.V., and Ryabykh, T.P. (2003). Melatonin modulates the action of near infrared radiation on cell adhesion. J. Pineal Res. 34, 167-172.

Katsuno, M., Adachi, H., Waza, M., Banno, H., Suzuki, K., Tanaka, F., Doyu, M., and Sobue, G. (2006). Pathogenesis, animal models and therapeutics in spinal and bulbar muscular atrophy (SBMA). Exp. Neurol. 200, 8-18.

Kawaguchi, Y., Kovacs, J.J., McLaurin, A., Vance, J.M., Ito, A., and Yao, T.P. (2003). The deacetylase HDAC6 regulates aggresome formation and cell viability in response to misfolded protein stress. Cell 115, 727-738.

Kaytor, M.D., Wilkinson, K.D., and Warren, S.T. (2004). Modulating huntingtin half-life alters polyglutaminedependent aggregate formation and cell toxicity. J. Neurochem. 89, 962-973. https://doi.org/10.1111/ j.1471-4159.2004.02376.x.

Keeney, P.M., Xie, J., Capaldi, R.A., and Bennett, J.P. (2006). Parkinson's disease brain mitochondrial complex I has oxidatively damaged subunits and is functionally impaired and misassembled. J. Neurosci. 26, 5256-5264. https://doi.org/10.1523/jneurosci.0984-06.2006.

Kessler, D.S., Levy, D.E., and Darnell, J.E. (1988). 2 interferon-induced nuclear factors bind a single promoter element in interferon-stimulated genes. Proc. Natl. Acad. Sci. U.S.A. 85, 8521-8525. https://doi. org/10.1073/pnas.85.22.8521.

Kfoury, N., Holmes, B.B., Jiang, H., Holtzman, D.M., and Diamond, M.I. (2012). Trans-cellular propagation of Tau aggregation by fibrillar species. J. Biol. Chem. 287, 19440-19451. https://doi.org/10.1074/jbc. M112.346072.

Khan, M.A.I., Respondek, M., Kjellström, S., Deep, S., Linse, S., and Akke, M. (2017). Cu/Zn superoxide dismutase forms amyloid fibrils under near-physiological quiescent conditions: the roles of disulfide bonds and effects of denaturant. ACS Chem. Neurosci. 8, 2019-2026. https://doi.org/10.1021/acschemneuro.7b00162.

Kim, S.H., Shanware, N.P., Bowler, M.J., and Tibbetts, R.S. (2010). Amyotrophic lateral sclerosis-associated proteins TDP-43 and FUS/TLS function in a common biochemical complex to co-regulate HDAC6 mRNA. J. Biol. Chem. 285, 34097-34105. https://doi. org/10.1074/jbc.M110.154831.

Kim, W., Bennett, E.J., Huttlin, E.L., Guo, A., Li, J., Possemato, A., Sowa, M.E., Rad, R., Rush, J., Comb, M.J., et al. (2011). Systematic and quantitative assessment of the ubiquitin-modified proteome. Mol. Cell 44, 325340. https://doi.org/10.1016/j.molcel.2011.08.025.

Kimber, T.E., Blumbergs, P.C., Rice, J.P., Hallpike, J.F., Edis, R., Thompson, P.D., and Suthers, G. (1998). Familial neuronal intranuclear inclusion disease with ubiquitin positive inclusions. J. Neurol. Sci. 160, 33-40.

Komander, D., Clague, M.J., and Urbé, S. (2009). Breaking the chains: structure and function of the deubiquitinases. Nat. Rev. Mol. Cell Biol. 10, 550-563. https://doi. org/10.1038/nrm2731.

Köpke, E., Tung, Y.C., Shaikh, S., Alonso, A.C., Iqbal, K., and Grundke-Iqbal, I. (1993). Microtubule-associated protein tau. Abnormal phosphorylation of a non-paired helical filament pool in Alzheimer disease. J. Biol. Chem. $268,24374-24384$. 
Kota, V., Sommer, G., Durette, C., Thibault, P., van Niekerk, E.A., Twiss, J.L., and Heise, T. (2016). SUMOModification of the La Protein Facilitates Binding to mRNA In Vitro and in Cells. PLOS ONE 11, e0156365. https://doi.org/10.1371/journal.pone.0156365.

Kota, V., Sommer, G., Hazard, E.S., Hardiman, G., Twiss, J.L., and Heise, T. (2018). SUMO modification of the RNA-binding protein La regulates cell proliferation and STAT3 protein stability. Mol. Cell. Biol. 38, e00129-17.

Kraft, C., Peter, M., and Hofmann, K. (2010). Selective autophagy: ubiquitin-mediated recognition and beyond. Nat. Cell Biol. 12, 836-841. https://doi.org/10.1038/ ncb0910-836.

Kristiansen, M., Messenger, M.J., Klöhn, P.C., Brandner, S., Wadsworth, J.D., Collinge, J., and Tabrizi, S.J. (2005). Disease-related prion protein forms aggresomes in neuronal cells leading to caspase activation and apoptosis. J. Biol. Chem. 280, 38851-38861.

Krüger, R., Kuhn, W., Müller, T., Woitalla, D., Graeber, M., Kösel, S., Przuntek, H., Epplen, J.T., Schöls, L., and Riess, O. (1998). Ala30Pro mutation in the gene encoding alpha-synuclein in Parkinson's disease. Nat. Genet. 18, 106-108. https://doi.org/10.1038/ng0298-106.

Krumova, P., Meulmeester, E., Garrido, M., Tirard, M., Hsiao, H.H., Bossis, G., Urlaub, H., Zweckstetter, M., Kügler, S., Melchior, F., et al. (2011). Sumoylation inhibits alpha-synuclein aggregation and toxicity. J. Cell Biol. 194, 49-60. https://doi.org/10.1083/ jcb.201010117.

Kunadt, M., Eckermann, K., Stuendl, A., Gong, J., Russo, B., Strauss, K., Rai, S., Kügler, S., Falomir Lockhart, L., Schwalbe, M., et al. (2015). Extracellular vesicle sorting of $\alpha$-Synuclein is regulated by sumoylation. Acta Neuropathol. 129, 695-713. https://doi.org/10.1007/ s00401-015-1408-1.

Kwiatkowski, T.J., Bosco, D.A., Leclerc, A.L., Tamrazian, E., Vanderburg, C.R., Russ, C., Davis, A., Gilchrist, J., Kasarskis, E.J., Munsat, T., et al. (2009). Mutations in the FUS/TLS gene on chromosome 16 cause familial amyotrophic lateral sclerosis. Science 323, 1205-1208. https://doi.org/10.1126/science.1166066.

LaFerla, F.M., Green, K.N., and Oddo, S. (2007). Intracellular amyloid-beta in Alzheimer's disease. Nat. Rev. Neurosci. 8, 499-509.

Lallemand-Breitenbach, V., Jeanne, M., Benhenda, S., Nasr, R., Lei, M., Peres, L., Zhou, J., Zhu, J., Raught, B., and de Thé, H. (2008). Arsenic degrades PML or PMLRARalpha through a SUMO-triggered RNF4/ubiquitinmediated pathway. Nat. Cell Biol. 10, 547-555. https:// doi.org/10.1038/ncb1717.

Lammich, S., Kojro, E., Postina, R., Gilbert, S., Pfeiffer, R., Jasionowski, M., Haass, C., and Fahrenholz, F. (1999). Constitutive and regulated alpha-secretase cleavage of Alzheimer's amyloid precursor protein by a disintegrin metalloprotease. Proc. Natl. Acad. Sci. U.S.A. 96, 39223927. https://doi.org/10.1073/pnas.96.7.3922.

Lantos, P.L. (1998). The definition of multiple system atrophy: a review of recent developments.J. Neuropathol. Exp. Neurol. 57, 1099-1111.

Lee, D.H., and Goldberg, A.L. (1998). Proteasome inhibitors: valuable new tools for cell biologists. Trends Cell Biol. 8, 397-403. https://doi.org/10.1016/s09628924(98)01346-4.
Lee, F.K.M., Wong, A.K.Y., Lee, Y.W., Wan, O.W., Chan, H.Y.E., and Chung, K.K.K. (2009). The role of ubiquitin linkages on alpha-synuclein induced-toxicity in a Drosophila model of Parkinson's disease. J. Neurochem. 110, 208-219. https://doi.org/10.1111/j.14714159.2009.06124.x.

Lee, J.T., Wheeler, T.C., Li, L., and Chin, L.S. (2008). Ubiquitination of alpha-synuclein by Siah-1 promotes alpha-synuclein aggregation and apoptotic cell death. Hum. Mol. Genet. 17, 906-917.

Lee, L., Sakurai, M., Matsuzaki, S., Arancio, O., and Fraser, P. (2013). SUMO and Alzheimer's disease. Neuromolecular Med. 15, 720-736. https://doi. org/10.1007/s12017-013-8257-7.

Lee, L., Dale, E., Staniszewski, A., Zhang, H., Saeed, F., Sakurai, M., Fa, M., Orozco, I., Michelassi, F., Akpan, N., et al. (2014). Regulation of synaptic plasticity and cognition by SUMO in normal physiology and Alzheimer's disease. Sci. Rep. 4. https://doi. org/10.1038/srep07190.

Li, Y., Wang, H., Wang, S., Quon, D., Liu, Y.W., and Cordell, B. (2003). Positive and negative regulation of APP amyloidogenesis by sumoylation. Proc. Natl. Acad. Sci. U.S.A. 100, 259-264. https://doi.org/10.1073/ pnas.0235361100.

Liang, Y.C., Lee, C.C., Yao, Y.L., Lai, C.C., Schmitz, M.L., and Yang, W.M. (2016). SUMO5, a Novel Poly-SUMO Isoform, Regulates PML Nuclear Bodies. Sci. Rep. 6, 26509. https://doi.org/10.1038/srep26509.

Lichtenthaler, S.F., Haass, C., and Steiner, H. (2011). Regulated intramembrane proteolysis - lessons from amyloid precursor protein processing. J. Neurochem. 117, 779-796. https://doi.org/10.1111/j.14714159.2011.07248.x.

Lieberman, A.P., Robitaille, Y., Trojanowski, J.Q. Dickson, D.W., and Fischbeck, K.H. (1998). Polyglutaminecontaining aggregates in neuronal intranuclear inclusion disease. Lancet 351, 884 .

Lieberman, A.P., Trojanowski, J.Q., Leonard, D.G., Chen, K.L., Barnett, J.L., Leverenz, J.B., Bird, T.D., Robitaille, Y., Malandrini, A., and Fischbeck, K.H. (1999). Ataxin 1 and ataxin 3 in neuronal intranuclear inclusion disease. Ann. Neurol. 46, 271-273.

Liebman, S.W., and Chernoff, Y.O. (2012). Prions in yeast. Genetics 191, 1041-1072. https://doi.org/10.1534/ genetics.111.137760.

Lin, H., Zhai, J., and Schlaepfer, W.W. (2005). RNA-binding protein is involved in aggregation of light neurofilament protein and is implicated in the pathogenesis of motor neuron degeneration. Hum. Mol. Genet. 14, 3643-3659.

Liu, S., Ninan, I., Antonova, I., Battaglia, F., Trinchese, F., Narasanna, A., Kolodilov, N., Dauer, W., Hawkins, R.D., and Arancio, O. (2004). alpha-Synuclein produces a long-lasting increase in neurotransmitter release. EMBO J. 23, 4506-4516.

Liu, S., Fa, M., Ninan, I., Trinchese, F., Dauer, W., and Arancio, O. (2007). Alpha-synuclein involvement in hippocampal synaptic plasticity: role of NO, cGMP, cGK and CaMKII. Eur. J. Neurosci. 25, 3583-3596.

Lührs, T., Ritter, C., Adrian, M., Riek-Loher, D., Bohrmann, B., Döbeli, H., Schubert, D., and Riek, R. (2005). 3D structure of Alzheimer's amyloid-beta(1-42) fibrils. Proc. Natl. Acad. Sci. U.S.A. 102, 17342-17347. 
Luo, H.B., Xia, Y.Y., Shu, X.J., Liu, Z.C., Feng, Y., Liu, X.H., Yu, G., Yin, G., Xiong, Y.S., Zeng, K., et al. (2014). SUMOylation at K340 inhibits tau degradation through deregulating its phosphorylation and ubiquitination. Proc. Natl. Acad. Sci. U.S.A. 111, 16586-16591. https:/ / doi.org/10.1073/pnas.1417548111.

Ma, J., and Lindquist, S. (2002). Conversion of PrP to a selfperpetuating PrPSc-like conformation in the cytosol. Science 298, 1785-1788. https://doi.org/10.1126/ science.1073619.

MacDonald, M.E., and Gusella, J.F. (1996). Huntington's disease: translating a CAG repeat into a pathogenic mechanism. Curr. Opin. Neurobiol. 6, 638-643.

Mackenzie, I.R., Neumann, M., Bigio, E.H., Cairns, N.J., Alafuzoff, I., Kril, J., Kovacs, G.G., Ghetti, B., Halliday, G., Holm, I.E., et al. (2010). Nomenclature and nosology for neuropathologic subtypes of frontotemporal lobar degeneration: an update. Acta Neuropathol. 119, 1-4. https://doi.org/10.1007/s00401-009-0612-2.

Mahajan, R., Delphin, C., Guan, T., Gerace, L., and Melchior, F. (1997). A small ubiquitin-related polypeptide involved in targeting RanGAP1 to nuclear pore complex protein RanBP2. Cell 88, 97-107.

Mandelkow, E.M., Biernat, J., Drewes, G., Gustke, N., Trinczek, B., and Mandelkow, E. (1995). Tau domains, phosphorylation, and interactions with microtubules. Neurobiol. Aging 16, 355-362. https://doi. org/10.1016/0197-4580(95)00025-a.

Mann, M., and Jensen, O.N. (2003). Proteomic analysis of post-translational modifications. Nat. Biotechnol. 21, 255-261. https://doi.org/10.1038/nbt0303-255.

Matsuo, A., Akiguchi, I., Lee, G.C., McGeer, E.G., McGeer, P.L., and Kimura, J. (1998). Myelin degeneration in multiple system atrophy detected by unique antibodies. Am. J. Pathol. 153, 735-744.

Mayer, R.J., Lowe, J., Lennox, G., Landon, M., MacLennan, K., and Doherty, F.J. (1989). Intermediate filamentubiquitin diseases: implications for cell sanitization. Biochem. Soc. Symp. 55, 193-201.

Maynard, C.J., Böttcher, C., Ortega, Z., Smith, R., Florea, B.I., Díaz-Hernández, M., Brundin, P., Overkleeft, H.S., Li, J.Y., Lucas, J.J., et al. (2009). Accumulation of ubiquitin conjugates in a polyglutamine disease model occurs without global ubiquitin/proteasome system impairment. Proc. Natl. Acad. Sci. U.S.A. 106, 1398613991. https://doi.org/10.1073/pnas.0906463106.

McFadden, K., Hamilton, R.L., Insalaco, S.J., Lavine, L., Al-Mateen, M., Wang, G., and Wiley, C.A. (2005). Neuronal intranuclear inclusion disease without polyglutamine inclusions in a child. J. Neuropathol. Exp. Neurol. 64, 545-552.

McKinley, M.P., Bolton, D.C., and Prusiner, S.B. (1983). A protease-resistant protein is a structural component of the scrapie prion. Cell 35, 57-62.

McKinnon, C., Goold, R., Andre, R., Devoy, A., Ortega, Z., Moonga, J., Linehan, J.M., Brandner, S., Lucas, J.J., Collinge, J., et al. (2016). Prion-mediated neurodegeneration is associated with early impairment of the ubiquitin-proteasome system. Acta Neuropathol. 131, 411-425. https://doi.org/10.1007/s00401-0151508-y.

McMillan, L.E., Brown, J.T., Henley, J.M., and Cimarosti, H. (2011). Profiles of SUMO and ubiquitin conjugation in an Alzheimer's disease model. Neurosci. Lett. 502, 201208. https://doi.org/10.1016/j.neulet.2011.07.045.

McWhirter, S.M., Tenoever, B.R., and Maniatis, T. (2005). Connecting mitochondria and innate immunity. Cell $122,645-647$.

Mead, S. (2006). Prion disease genetics. Eur. J. Hum. Genet. $14,273-281$.

Melchior, F. (2000). SUMO - nonclassical ubiquitin. Annu. Rev. Cell Dev. Biol. 16, 591-626. https://doi. org/10.1146/annurev.cellbio.16.1.591.

Melchior, F., Schergaut, M., and Pichler, A. (2003). SUMO: ligases, isopeptidases and nuclear pores. Trends Biochem. Sci. 28, 612-618.

Meluh, P.B., and Koshland, D. (1995). Evidence that the MIF2 gene of Saccharomyces cerevisiae encodes a centromere protein with homology to the mammalian centromere protein CENP-C. Mol. Biol. Cell 6, 793807.

Mercado, P.A., Ayala, Y.M., Romano, M., Buratti, E., and Baralle, F.E. (2005). Depletion of TDP 43 overrides the need for exonic and intronic splicing enhancers in the human apoA-II gene. Nucleic Acids Res. 33, 6000-6010.

Meyer-Luehmann, M., Coomaraswamy, J., Bolmont, T., Kaeser, S., Schaefer, C., Kilger, E., Neuenschwander, A., Abramowski, D., Frey, P., Jaton, A.L., et al. (2006). Exogenous induction of cerebral beta-amyloidogenesis is governed by agent and host. Science 313, 1781-1784.

Michalik, A., and Van Broeckhoven, C. (2004). Proteasome degrades soluble expanded polyglutamine completely and efficiently. Neurobiol. Dis. 16, 202-211. https:// doi.org/10.1016/j.nbd.2003.12.020.

Mietelska-Porowska, A., Wasik, U., Goras, M., Filipek, A., and Niewiadomska, G. (2014). Tau protein modifications and interactions: their role in function and dysfunction. Int. J. Mol. Sci. 15, 4671-4713. https://doi. org/10.3390/ijms15034671.

Mitra, S., Tsvetkov, A.S., and Finkbeiner, S. (2009). Single neuron ubiquitin-proteasome dynamics accompanying inclusion body formation in huntington disease. J. Biol. Chem. 284, 4398-4403. https://doi.org/10.1074/jbc. M806269200.

Morishima, Y., Wang, A.M., Yu, Z., Pratt, W.B., Osawa, Y., and Lieberman, A.P. (2008). CHIP deletion reveals functional redundancy of E3 ligases in promoting degradation of both signaling proteins and expanded glutamine proteins. Hum. Mol. Genet. 17, 3942-3952. https://doi.org/10.1093/hmg/ddn296.

Morishima-Kawashima, M., Hasegawa, M., Takio, K., Suzuki, M., Titani, K., and Ihara, Y. (1993). Ubiquitin is conjugated with amino-terminally processed tau in paired helical filaments. Neuron 10, 1151-1160.

Morris, M., Knudsen, G.M., Maeda, S., Trinidad, J.C., Ioanoviciu, A., Burlingame, A.L., and Mucke, L. (2015). Tau post-translational modifications in wild-type and human amyloid precursor protein transgenic mice. Nat. Neurosci. 18, 1183-1189. https://doi.org/10.1038/ nn.4067.

Münch, C., O’Brien, J., and Bertolotti, A. (2011). Prionlike propagation of mutant superoxide dismutase-1 misfolding in neuronal cells. Proc. Natl. Acad. Sci. U.S.A. 108, 3548-3553. https://doi.org/10.1073/ pnas. 1017275108 . 
Mukherjee, S., Thomas, M., Dadgar, N., Lieberman, A.P., and Iñiguez-Lluhí, J.A. (2009). Small ubiquitin-like modifier (SUMO) modification of the androgen receptor attenuates polyglutamine-mediated aggregation. J. Biol. Chem. 284, 21296-21306. https://doi.org/10.1074/ jbc.M109.011494.

Mullan, M., Crawford, F., Axelman, K., Houlden, H., Lilius, L., Winblad, B., and Lannfelt, L. (1992). A pathogenic mutation for probable Alzheimer's disease in the APP gene at the N-terminus of beta-amyloid. Nat. Genet. 1, 345-347. https://doi.org/10.1038/ng0892-345.

Mullen, J.R., and Brill, S.J. (2008). Activation of the Slx5-Slx8 ubiquitin ligase by poly-small ubiquitin-like modifier conjugates. J. Biol. Chem. 283, 19912-19921. https://doi.org/10.1074/jbc.M802690200.

Murray, D.T., Kato, M., Lin, Y., Thurber, K.R., Hung, I., McKnight, S.L., and Tycko, R. (2017). Structure of FUS protein fibrils and its relevance to self-assembly and phase separation of low-complexity domains. Cell 171, 615-627.e16.

Nacerddine, K., Lehembre, F., Bhaumik, M., Artus, J., Cohen-Tannoudji, M., Babinet, C., Pandolfi, P.P., and Dejean, A. (2005). The SUMO pathway is essential for nuclear integrity and chromosome segregation in mice. Dev. Cell 9, 769-779.

Neddens, J., Temmel, M., Flunkert, S., Kerschbaumer, B., Hoeller, C., Loeffler, T., Niederkofler, V., Daum, G., Attems, J., and Hutter-Paier, B. (2018). Phosphorylation of different tau sites during progression of Alzheimer's disease. Acta Neuropathol. Commun. 6, 52. https://doi. org/10.1186/s40478-018-0557-6.

Neef, D., and Walling, A.D. (2006). Dementia with Lewy bodies: an emerging disease. Am. Fam. Physician 73, 1223-1229.

Neumann, M., Sampathu, D.M., Kwong, L.K., Truax, A.C., Micsenyi, M.C., Chou, T.T., Bruce, J., Schuck, T., Grossman, M., Clark, C.M., et al. (2006). Ubiquitinated TDP-43 in frontotemporal lobar degeneration and amyotrophic lateral sclerosis. Science 314, 130-133.

Neumann, M., Rademakers, R., Roeber, S., Baker, M., Kretzschmar, H.A., and Mackenzie, I.R.A. (2009). A new subtype of frontotemporal lobar degeneration with FUS pathology. Brain 132, 2922-2931. https://doi. org/10.1093/brain/awp214.

Niikura, T., Kita, Y., and Abe, Y. (2014). SUMO3 modification accelerates the aggregation of ALS-linked SOD1 mutants. PLOS ONE 9, e101080. https://doi. org/10.1371/journal.pone.0101080.

Nishida, T., and Yasuda, H. (2002). PIAS1 and PIASx alpha function as SUMO-E3 ligases toward androgen receptor and repress androgen receptor-dependent transcription. J. Biol. Chem. 277, 41311-41317. https://doi. org/10.1074/jbc.M206741200.

Nistico, R., Ferraina, C., Marconi, V., Blandini, F., Negri, L., Egebjerg, J., and Feligioni, M. (2014). Age-related changes of protein SUMOylation balance in the A beta PP Tg2576 mouse model of Alzheimer's disease. Front. Pharmacol. 5, 63. https://doi.org/10.3389/ fphar.2014.00063.

Nonaka, T., Iwatsubo, T., and Hasegawa, M. (2005). Ubiquitination of alpha-synuclein. Biochemistry 44, 361-368. https://doi.org/10.1021/bi0485528.
O'Brien, R.J., and Wong, P.C. (2011). Amyloid precursor protein processing and Alzheimer's disease. Ann. Rev. Neurosci. 34, 185-204. https://doi.org/10.1146/ annurev-neuro-061010-113613.

Oh, Y., Kim, Y.M., Mouradian, M.M., and Chung, K.C. (2011). Human Polycomb protein 2 promotes a-synuclein aggregate formation through covalent SUMOylation. Brain Res. 1381, 78-89. https://doi. org/10.1016/j.brainres.2011.01.039.

Olsen, J.V., Blagoev, B., Gnad, F., Macek, B., Kumar, C., Mortensen, P., and Mann, M. (2006). Global, in vivo, and site-specific phosphorylation dynamics in signaling networks. Cell 127, 635-648.

O’Rourke, J.G., Gareau, J.R., Ochaba, J., Song, W., Raskó, T., Reverter, D., Lee, J., Monteys, A.M., Pallos, J., Mee, L., et al. (2013). SUMO-2 and PIAS1 modulate insoluble mutant huntingtin protein accumulation. Cell Rep. 4, 362-375. https://doi.org/10.1016/j. celrep.2013.06.034.

Ortega, Z., Díaz-Hernández, M., Maynard, C.J., Hernández, F., Dantuma, N.P., and Lucas, J.J. (2010). Acute polyglutamine expression in inducible mouse model unravels ubiquitin/proteasome system impairment and permanent recovery attributable to aggregate formation. J. Neurosci. 30, 3675-3688. https://doi.org/10.1523/ JNEUROSCI.5673-09.2010.

Owerbach, D., McKay, E.M., Yeh, E.T., Gabbay, K.H., and Bohren, K.M. (2005). A proline-90 residue unique to SUMO-4 prevents maturation and sumoylation. Biochem. Biophys. Res. Commun. 337, 517-520.

Panse, V.G., Hardeland, U., Werner, T., Kuster, B., and Hurt, E. (2004). A proteome-wide approach identifies sumoylated substrate proteins in yeast. J. Biol. Chem. 279, 41346-41351. https://doi.org/10.1074/jbc. M407950200.

Papp, M.I., Kahn, J.E., and Lantos, P.L. (1989). Glial cytoplasmic inclusions in the CNS of patients with multiple system atrophy (striatonigral degeneration, olivopontocerebellar atrophy and Shy-Drager syndrome). J. Neurol. Sci. 94, 79-100.

Pavlopoulos, E., Trifilieff, P., Chevaleyre, V., Fioriti, L., Zairis, S., Pagano, A., Malleret, G., and Kandel, E.R. (2011). Neuralized1 activates CPEB3: a function for nonproteolytic ubiquitin in synaptic plasticity and memory storage. Cell 147, 1369-1383. https://doi. org/10.1016/j.cell.2011.09.056.

Pearson, H.A., and Peers, C. (2006). Physiological roles for amyloid beta peptides. J. Phys. 575, 5-10. https://doi. org/10.1113/jphysiol.2006.111203.

Peng, J., Schwartz, D., Elias, J.E., Thoreen, C.C., Cheng, D., Marsischky, G., Roelofs, J., Finley, D., and Gygi, S.P. (2003). A proteomics approach to understanding protein ubiquitination. Nat. Biotechnol. 21, 921-926. https://doi.org/10.1038/nbt849.

Pennuto, M., Palazzolo, I., and Poletti, A. (2009). Posttranslational modifications of expanded polyglutamine proteins: impact on neurotoxicity. Hum. Mol. Genet. 18, R40-R47. https://doi.org/10.1093/hmg/ddn412.

Piccardo, P., Cervenak, J., Bu, M., Miller, L., and Asher, D.M. (2014). Complex proteinopathy with accumulations of prion protein, hyperphosphorylated tau, alphasynuclein and ubiquitin in experimental bovine spongiform encephalopathy of monkeys. J. Gen. Virol. 
95, 1612-1618. https://doi.org/10.1099/vir.0.0620830.

Pickart, C.M. (2001). Mechanisms underlying ubiquitination. Annu. Rev. Biochem. 70, 503-533.

Poirier, M.A.,Li, H., Macosko, J., Cai, S., Amzel, M., and Ross, C.A. (2002). Huntingtin spheroids and protofibrils as precursors in polyglutamine fibrilization. J. Biol. Chem. 277, 41032-41037. https://doi.org/10.1074/jbc. M205809200.

Polymeropoulos, M.H., Lavedan, C., Leroy, E., Ide, S.E., Dehejia, A., Dutra, A., Pike, B., Root, H., Rubenstein, J., Boyer, R., et al. (1997). Mutation in the alpha-synuclein gene identified in families with Parkinson's disease. Science 276, 2045-2047.

Potts, P.R., and Yu, H. (2005). Human MMS21/NSE2 is a SUMO ligase required for DNA repair. Mol. Cell. Biol. 25, 7021-7032.

Poukka, H., Karvonen, U., Janne, O.A., and Palvimo, J.J. (2000). Covalent modification of the androgen receptor by small ubiquitin-like modifier 1 (SUMO-1). Proc. Natl. Acad. Sci. U.S.A. 97, 14145-14150. https://doi. org/10.1073/pnas.97.26.14145.

Pountney, D.L., Chegini, F., Shen, X., Blumbergs, P.C., and Gai, W.P. (2005a). SUMO-1 marks subdomains within glial cytoplasmic inclusions of multiple system atrophy. Neurosci. Lett. 381, 74-79.

Pountney, D.L., Voelcker, N.H., and Gai, W.P. (2005b). Annular alpha-synuclein oligomers are potentially toxic agents in alpha-synucleinopathy. Hypothesis. Neurotox. Res. 7, 59-67.

Pratt, G., and Rechsteiner, M. (2008). Proteasomes cleave at multiple sites within polyglutamine tracts - Activation by PA28 gamma(K188E). J. Biol. Chem. 283, 1291912925. https://doi.org/10.1074/jbc.M709347200.

Prusiner, S.B. (1982). Novel proteinaceous infectious particles cause scrapie. Science 216, 136-144.

Prusiner, S.B. (2013). Biology and genetics of prions causing neurodegeneration. Annu. Rev. Genet. 47, 601-623. https://doi.org/10.1146/annurevgenet-110711-155524.

Prusiner, S.B., McKinley, M.P., Bowman, K.A., Bolton, D.C., Bendheim, P.E., Groth, D.F., and Glenner, G.G. (1983). Scrapie prions aggregate to form amyloidlike birefringent rods. Cell 35, 349-358. https://doi. org/10.1016/0092-8674(83)90168-x.

Ren, P.H., Lauckner, J.E., Kachirskaia, I., Heuser, J.E., Melki, R., and Kopito, R.R. (2009). Cytoplasmic penetration and persistent infection of mammalian cells by polyglutamine aggregates. Nat. Cell Biol. 11, 219-225. https://doi.org/10.1038/ncb1830.

Rhoads, S.N., Monahan, Z.T., Yee, D.S., and Shewmaker, F.P. (2018). The role of post-translational modifications on prion-like aggregation and liquid-phase separation of FUS. Int. J. Mol. Sci. 19, E886.

Riley, B.E.,Zoghbi, H.Y., and Orr, H.T. (2005). SUMOylation of the polyglutamine repeat protein, ataxin-1, is dependent on a functional nuclear localization signal. J. Biol. Chem. 280, 21942-21948.

Rodriguez, M.S., Dargemont, C., and Hay, R.T. (2001). SUMO-1 conjugation in vivo requires both a consensus modification motif and nuclear targeting. J. Biol. Chem.
276, 12654-12659. https://doi.org/10.1074/jbc. M009476200.

Rose, A.S., Bradley, A.R., Valasatava, Y., Duarte, J.M., Prlic, A., and Rose, P.W. (2018). NGL viewer: web-based molecular graphics for large complexes. Bioinformatics 34, 3755-3758. https://doi.org/10.1093/ bioinformatics/bty419.

Rosen, D.R. (1993). Mutations in $\mathrm{Cu} / \mathrm{Zn}$ superoxide dismutase gene are associated with familial amyotrophic lateral sclerosis. Nature 364, 362. https://doi. org/10.1038/364362c0.

Ross, C.A. (2002). Polyglutamine pathogenesis: Emergence of unifying mechanisms for Huntington's disease and related disorders. Neuron 35, 819-822. https://doi. org/10.1016/s0896-6273(02)00872-3.

Ross, C.A., and Poirier, M.A. (2004). Protein aggregation and neurodegenerative disease. Nat. Med. 10, S10-7. https://doi.org/10.1038/nm1066.

Rotin, D., and Kumar, S. (2009). Physiological functions of the HECT family of ubiquitin ligases. Nat. Rev. Mol. Cell Biol. 10, 398-409. https://doi.org/10.1038/nrm2690.

Rutherford, N.J., Zhang, Y.J., Baker, M., Gass, J.M., Finch, N.A., Xu, Y.F., Stewart, H., Kelley, B.J., Kuntz, K., Crook, R.J., et al. (2008). Novel mutations in TARDBP (TDP43) in patients with familial amyotrophic lateral sclerosis. PLOS Genet. 4, e1000193. https://doi.org/10.1371/ journal.pgen.1000193.

Ryu, J., Cho, S., Park, B.C., and Lee, D.H. (2010). Oxidative stress-enhanced SUMOylation and aggregation of ataxin-1: Implication of JNK pathway. Biochem. Biophys. Res. Commun. 393, 280-285. https://doi. org/10.1016/j.bbrc.2010.01.122.

Safar, J.G., Kellings, K., Serban, A., Groth, D., Cleaver, J.E., Prusiner, S.B., and Riesner, D. (2005). Search for a prion-specific nucleic acid. J. Virol. 79, 10796-10806.

Sakamoto, K.M., Kim, K.B., Kumagai, A., Mercurio, F., Crews, C.M., and Deshaies, R.J. (2001). Protacs: chimeric molecules that target proteins to the Skp1-Cullin-F box complex for ubiquitination and degradation. Proc. Natl. Acad. Sci. U.S.A. 98, 85548559. https://doi.org/10.1073/pnas.141230798.

Sakamoto, M., Uchihara, T., Nakamura, A., Mizutani, T., and Mizusawa, H. (2005). Progressive accumulation of ubiquitin and disappearance of alpha-synuclein epitope in multiple system atrophy-associated glial cytoplasmic inclusions: triple fluorescence study combined with Gallyas-Braak method. Acta Neuropathol. 110, 417425. https://doi.org/10.1007/s00401-005-1066-9.

Sampson, D.A., Wang, M., and Matunis, M.J. (2001). The small ubiquitin-like modifier-1 (SUMO-1) consensus sequence mediates Ubc9 binding and is essential for SUMO-1 modification. J. Biol. Chem. 276, $21664-$ 21669. https://doi.org/10.1074/jbc.M100006200.

Saudou, F., Finkbeiner, S., Devys, D., and Greenberg, M.E. (1998). Huntingtin acts in the nucleus to induce apoptosis but death does not correlate with the formation of intranuclear inclusions. Cell 95, 55-66.

Scheckel, C., and Aguzzi, A. (2018). Prions, prionoids and protein misfolding disorders. Nat. Rev. Genet. 19, 405418. https://doi.org/10.1038/s41576-018-0011-4. 
Schilling, G., Wood, J.D., Duan, K., Slunt, H.H., Gonzales, V., Yamada, M., Cooper, J.K., Margolis, R.L., Jenkins, N.A., Copeland, N.G., et al. (1999). Nuclear accumulation of truncated atrophin-1 fragments in a transgenic mouse model of DRPLA. Neuron 24, 275-286.

Schipper-Krom, S., Juenemann, K., Jansen, A.H., Wiemhoefer, A., van den Nieuwendijk, R., Smith, D.L., Hink, M.A., Bates, G.P., Overkleeft, H., Ovaa, H., et al. (2014). Dynamic recruitment of active proteasomes into polyglutamine initiated inclusion bodies. FEBS Lett. 588, 151-159. https://doi.org/10.1016/j. febslet.2013.11.023.

Schulman, B.A., and Harper, J.W. (2009). Ubiquitinlike protein activation by E1 enzymes: the apex for downstream signalling pathways. Nat. Rev. Mol. Cell Biol. 10, 319-331. https://doi.org/10.1038/nrm2673.

Schweers, O., Schönbrunn-Hanebeck, E., Marx, A., and Mandelkow, E. (1994). Structural studies of tau protein and Alzheimer paired helical filaments show no evidence for beta-structure. J. Biol. Chem. 269, 24290-24297.

Seelaar, H., Klijnsma, K.Y., de Koning, I., van der Lugt, A., Chiu, W.Z., Azmani, A., Rozemuller, A.J., and van Swieten, J.C. (2010). Frequency of ubiquitin and FUS-positive, TDP-43-negative frontotemporal lobar degeneration. J. Neurol. 257, 747-753. https://doi. org/10.1007/s00415-009-5404-z.

Seet, B.T., Dikic, I., Zhou, M.M., and Pawson, T. (2006). Reading protein modifications with interaction domains. Nat. Rev. Mol. Cell Biol. 7, 473-483.

Serpell, L. (2014). Amyloid structure. Essays Biochem. 56, 1-10. https://doi.org/10.1042/bse0560001.

Serpell, L.C. (2000). Alzheimer's amyloid fibrils: structure and assembly. Biochim. Biophys. Acta 1502, 16-30. https://doi.org/10.1016/s0925-4439(00)00029-6.

Serpell, L.C., Berriman, J., Jakes, R., Goedert, M., and Crowther, R.A. (2000). Fiber diffraction of synthetic alpha-synuclein filaments shows amyloid-like crossbeta conformation. Proc. Natl. Acad. Sci. U.S.A. 97, 4897-4902.

Seyfried, N.T., Gozal, Y.M., Dammer, E.B., Xia, Q. Duong, D.M., Cheng, D., Lah, J.J., Levey, A.I., and Peng, J. (2010). Multiplex SILAC analysis of a cellular TDP-43 proteinopathy model reveals protein inclusions associated with SUMOylation and diverse polyubiquitin chains. Mol. Cell Proteomics 9, 705-718. https://doi. org/10.1074/mcp.M800390-MCP200.

Shahpasandzadeh, H., Popova, B., Kleinknecht, A., Fraser, P.E., Outeiro, T.F., and Braus, G.H. (2014). Interplay between sumoylation and phosphorylation for protection against $\alpha$-synuclein inclusions. J. Biol. Chem. 289, 31224-31240. https://doi.org/10.1074/jbc. M114.559237.

Sharma, A., Lyashchenko, A.K., Lu, L., Nasrabady, S.E., Elmaleh, M., Mendelsohn, M., Nemes, A., Tapia, J.C., Mentis, G.Z., and Shneider, N.A. (2016). ALSassociated mutant FUS induces selective motor neuron degeneration through toxic gain of function. Nat. Commun. 7, 10465. https://doi.org/10.1038/ ncomms 10465 .

Shimura, H., Schwartz, D., Gygi, S.P., and Kosik, K.S. (2004). CHIP-Hsc70 complex ubiquitinates phosphorylated tau and enhances cell survival. J. Biol. Chem. 279, 48694876. https://doi.org/10.1074/jbc.M305838200.
Shirakura, H., Hayashi, N., Ogino, S., Tsuruma, K., Uehara, T., and Nomura, Y. (2005). Caspase recruitment domain of procaspase- 2 could be a target for SUMO-1 modification through Ubc9. Biochem. Biophys. Res. Commun. 331, 1007-1015.

Si, K., Choi, Y.B., White-Grindley, E., Majumdar, A., and Kandel, E.R. (2010). Aplysia CPEB can form prionlike multimers in sensory neurons that contribute to long-term facilitation. Cell 140, 421-435. https://doi. org/10.1016/j.cell.2010.01.008.

Smit, J.J., and Sixma, T.K. (2014). RBR E3-ligases at work. EMBO Rep. 15, 142-154. https://doi.org/10.1002/ embr.201338166.

Snyder, H., Mensah, K., Theisler, C., Lee, J., Matouschek, A., and Wolozin, B. (2003). Aggregated and monomeric alpha-synuclein bind to the S6' proteasomal protein and inhibit proteasomal function. J. Biol. Chem. 278, 1175311759. https://doi.org/10.1074/jbc.M208641200.

Son, M., Cloyd, C.D., Rothstein, J.D., Rajendran, B., and Elliott, J.L. (2003). Aggregate formation in $\mathrm{Cu}, \mathrm{Zn}$ superoxide dismutase-related proteins. J. Biol. Chem. 278, 14331-14336. https://doi.org/10.1074/jbc. M211698200.

Speldewinde, S.H., Doronina, V.A., and Grant, C.M. (2015). Autophagy protects against de novo formation of the [PSI+] prion in yeast. Mol. Biol. Cell 26, 4541-4551. https://doi.org/10.1091/mbc.E15-08-0548.

Spillantini, M.G., and Goedert, M. (2000). The alphasynucleinopathies: Parkinson's disease, dementia with Lewy bodies, and multiple system atrophy. Ann. N.Y. Acad. Sci. 920, 16-27.

Spillantini, M.G., Schmidt, M.L., Lee, V.M.Y., Trojanowski, J.Q. Jakes, R., and Goedert, M. (1997). alpha-synuclein in Lewy bodies. Nature 388, 839-840. https://doi. org/10.1038/42166.

Sreedharan, J., Blair, I.P., Tripathi, V.B., Hu, X., Vance, C., Rogelj, B., Ackerley, S., Durnall, J.C., Williams, K.L., Buratti, E., et al. (2008). TDP-43 mutations in familial and sporadic amyotrophic lateral sclerosis. Science 319, 1668-1672. https://doi.org/10.1126/science.1154584.

Stankova, T., Piepkorn, L., Bayer, T.A., Jahn, O., and Tirard, M. (2018). SUMO1-conjugation is altered during normal aging but not by increased amyloid burden. Aging Cell [Epub ahead of print]. https://doi. org/10.1111/acel.12760.

Stansfield, I., Eurwilaichitr, L., Akhmaloka, and Tuite, M.F. (1996). Depletion in the levels of the release factor eRF1 causes a reduction in the efficiency of translation termination in yeast. Mol. Microbiol. 20, 1135-1143. https://doi.org/10.1111/j.1365-2958.1996.tb02634.x.

Stefanis, L., Larsen, K.E., Rideout, H.J., Sulzer, D., and Greene, L.A. (2001). Expression of A53T mutant but not wild-type alpha-synuclein in PC12 cells induces alterations of the ubiquitin-dependent degradation system, loss of dopamine release, and autophagic cell death. J. Neurosci. 21, 9549-9560. https://doi. org/10.1523/jneurosci.21-24-09549.2001.

Steffan, J.S., Agrawal, N., Pallos, J., Rockabrand, E., Trotman, L.C., Slepko, N., Illes, K., Lukacsovich, T., Zhu, Y.Z., Cattaneo, E., et al. (2004). SUMO modification of Huntingtin and Huntington's disease pathology. Science 304, 100-104. https://doi.org/10.1126/ science.1092194. 
Stein, K.C., and True, H.L. (2011). The $[\mathrm{RNQ+}]$ prion: a model of both functional and pathological amyloid. Prion 5, 291-298. https://doi.org/10.4161/pri.18213.

Stephan, J.S., Fioriti, L., Lamba, N., Colnaghi, L., Karl, K., Derkatch, I.L., and Kandel, E.R. (2015). The cpeb3 protein is a functional prion that interacts with the actin cytoskeleton. Cell Rep. 11, 1772-1785. https://doi. org/10.1016/j.celrep.2015.04.060.

Strong, M.J., Volkening, K., Hammond, R., Yang, W., Strong, W., Leystra-Lantz, C., and Shoesmith, C. (2007). TDP43 is a human low molecular weight neurofilament (hNFL) mRNA-binding protein. Mol. Cell. Neurosci. 35, 320-327.

Sung, J.H., Ramirez-Lassepas, M., Mastri, A.R., and Larkin, S.M. (1980). An unusual degenerative disorder of neurons associated with a novel intranuclear hyaline inclusion (neuronal intranuclear hyaline inclusion disease). A clinicopathological study of a case. J. Neuropathol. Exp. Neurol. 39, 107-130.

Swatek, K.N., and Komander, D. (2016). Ubiquitin modifications. Cell Res. 26, 399-422. https://doi. org/10.1038/cr.2016.39.

Takahashi-Fujigasaki, J., Arai, K., Funata, N., and Fujigasaki, H. (2006). SUMOylation substrates in neuronal intranuclear inclusion disease. Neuropathol. Appl. Neurobiol. 32, 92-100.

Tank, E.M., and True, H.L. (2009). Disease-associated mutant ubiquitin causes proteasomal impairment and enhances the toxicity of protein aggregates. PLOS Genet. 5, e1000382. https://doi.org/10.1371/journal. pgen.1000382.

Tatham, M.H., Jaffray, E., Vaughan, O.A., Desterro, J.M., Botting, C.H., Naismith, J.H., and Hay, R.T. (2001). Polymeric chains of SUMO-2 and SUMO-3 are conjugated to protein substrates by SAE1/SAE2 and Ubc9. J. Biol. Chem. 276, 35368-35374. https://doi. org/10.1074/jbc.M104214200.

Taylor, J.P., Hardy, J., and Fischbeck, K.H. (2002). Toxic proteins in neurodegenerative disease. Science 296, 1991-1995. https://doi.org/10.1126/science.1067122.

Terashima, T., Kawai, H., Fujitani, M., Maeda, K., and Yasuda, H. (2002). SUMO-1 co-localized with mutant atrophin-1 with expanded polyglutamines accelerates intranuclear aggregation and cell death. Neuroreport 13, 2359-2364. https://doi.org/10.1097/01. wnr.0000045009.30898.94.

Theodoraki, M.A., Nillegoda, N.B., Saini, J., and Caplan, A.J. (2012). A network of ubiquitin ligases is important for the dynamics of misfolded protein aggregates in yeast. J. Biol. Chem. 287, 23911-23922. https://doi. org/10.1074/jbc.M112.341164.

Tiraboschi, P., Hansen, L.A., Thal, L.J., and Corey-Bloom, J. (2004). The importance of neuritic plaques and tangles to the development and evolution of $\mathrm{AD}$. Neurology 62, 1984-1989.

Tofaris, G.K., Razzaq, A., Ghetti, B., Lilley, K.S., and Spillantini, M.G. (2003). Ubiquitination of alphasynuclein in Lewy bodies is a pathological event not associated with impairment of proteasome function. J. Biol. Chem. 278, 44405-44411. https://doi. org/10.1074/jbc.M308041200.

Tsai, Y.C., Fishman, P.S., Thakor, N.V., and Oyler, G.A. (2003). Parkin facilitates the elimination of expanded polyglutamine proteins and leads to preservation of proteasome function. J. Biol. Chem. 278, 22044-22055. https://doi.org/10.1074/jbc.M212235200.

Tsvetkov, A.S., Arrasate, M., Barmada, S., Ando, D.M., Sharma, P., Shaby, B.A., and Finkbeiner, S. (2013). Proteostasis of polyglutamine varies among neurons and predicts neurodegeneration. Nat. Chem. Biol. 9, 586-592. https://doi.org/10.1038/nchembio.1308.

Ueda, H., Goto, J., Hashida, H., Lin, X., Oyanagi, K., Kawano, H., Zoghbi, H.Y., Kanazawa, I., and Okazawa, H. (2002). Enhanced SUMOylation in polyglutamine diseases. Biochem. Biophys. Res. Commun. 293, 307-313. https://doi.org/10.1016/S0006-291X(02)00211-5.

Ulmer, T.S., Bax, A., Cole, N.B., and Nussbaum, R.L. (2005). 1XQ8: Human micelle-bound alpha-synuclein. J. Biol. Chem. 280, 9595-9603. https://doi.org/10.1074/jbc. M411805200.

Vance, C., Rogelj, B., Hortobágyi, T., De Vos, K.J., Nishimura, A.L., Sreedharan, J., Hu, X., Smith, B., Ruddy, D., Wright, P., et al. (2009). Mutations in FUS, an RNA processing protein, cause familial amyotrophic lateral sclerosis type 6. Science 323, 1208-1211. https://doi.org/10.1126/ science.1165942.

Van Deerlin, V.M., Leverenz, J.B., Bekris, L.M., Bird, T.D., Yuan, W., Elman, L.B., Clay, D., Wood, E.M., ChenPlotkin, A.S., Martinez-Lage, M., et al. (2008). TARDBP mutations in amyotrophic lateral sclerosis with TDP-43 neuropathology: a genetic and histopathological analysis. Lancet Neurol. 7, 409-416. https://doi. org/10.1016/S1474-4422(08)70071-1.

van der Kamp, M.W., and Daggett, V. (2009). The consequences of pathogenic mutations to the human prion protein. Protein Eng. Des. Sel. 22, 461-468. https://doi.org/10.1093/protein/gzp039.

Van Hoesen, G.W., Hyman, B.T., and Damasio, A.R. (1991). Entorhinal cortex pathology in Alzheimer's disease. Hippocampus 1, 1-8. https://doi.org/10.1002/ hipo.450010102.

van Niekerk, E.A., Willis, D.E., Chang, J.H., Reumann, K., Heise, T., and Twiss, J.L. (2007). Sumoylation in axons triggers retrograde transport of the RNA-binding protein La. Proc. Natl. Acad. Sci. U.S.A. 104, 12913-12918.

van Tijn, P., Dennissen, F.J.A., Gentier, R.J.G., Hobo, B., Hermes, D., Steinbusch, H.W.M., Van Leeuwen, F.W., and Fischer, D.F. (2012). Mutant ubiquitin decreases amyloid beta plaque formation in a transgenic mouse model of Alzheimer's disease. Neurochem. Int. 61, 739748. https://doi.org/10.1016/j.neuint.2012.07.007.

Veeriah, S., Taylor, B.S., Meng, S., Fang, F., Yilmaz, E., Vivanco, I., Janakiraman, M., Schultz, N., Hanrahan, A.J., Pao, W., et al. (2010). Somatic mutations of the Parkinson's disease-associated gene PARK2 in glioblastoma and other human malignancies. Nat. Genet. 42, 77-82. https://doi.org/10.1038/ng.491.

Venkatraman, P., Wetzel, R., Tanaka, M., Nukina, N., and Goldberg, A.L. (2004). Eukaryotic proteasomes cannot digest polyglutamine sequences and release them during degradation of polyglutamine-containing proteins. Mol. Cell 14, 95-104.

Verhoef, L.G., Lindsten, K., Masucci, M.G., and Dantuma, N.P. (2002). Aggregate formation inhibits proteasomal degradation of polyglutamine proteins. Hum. Mol. Genet. 11, 2689-2700. 
Vogler, T.O., Wheeler, J.R., Nguyen, E.D., Hughes, M.P., Britson, K.A., Lester, E., Rao, B., Betta, N.D., Whitney, O.N., Ewachiw, T.E., et al. (2018). TDP-43 and RNA form amyloid-like myo-granules in regenerating muscle. Nature 563, 508-513. https://doi.org/10.1038/ s41586-018-0665-2.

Wagner, S.A., Beli, P., Weinert, B.T., Nielsen, M.L., Cox, J., Mann, M., and Choudhary, C. (2011). A proteome-wide, quantitative survey of in vivo ubiquitylation sites reveals widespread regulatory roles. Mol. Cell Proteomics 10, M111.013284. https://doi.org/10.1074/mcp. M111.013284.

Wang, H.Y., Wang, I.F., Bose, J., and Shen, C.K. (2004). Structural diversity and functional implications of the eukaryotic TDP gene family. Genomics 83, 130-139. https://doi.org/10.1016/s0888-7543(03)00214-3.

Watanabe, M., Dykes-Hoberg, M., Culotta, V.C., Price, D.L., Wong, P.C., and Rothstein, J.D. (2001). Histological evidence of protein aggregation in mutant SOD1 transgenic mice and in amyotrophic lateral sclerosis neural tissues. Neurobiol. Dis. 8, 933-941. https://doi. org/10.1006/nbdi.2001.0443.

Watase, K., Weeber, E.J., Xu, B., Antalffy, B., Yuva-Paylor, L., Hashimoto, K., Kano, M., Atkinson, R., Sun, Y., Armstrong, D.L., et al. (2002). A long CAG repeat in the mouse Scal locus replicates SCA1 features and reveals the impact of protein solubility on selective neurodegeneration. Neuron 34, 905-919.

Watts, G.D., Wymer, J., Kovach, M.J., Mehta, S.G., Mumm, S., Darvish, D., Pestronk, A., Whyte, M.P., and Kimonis, V.E. (2004). Inclusion body myopathy associated with Paget disease of bone and frontotemporal dementia is caused by mutant valosin-containing protein. Nat. Genet. 36, 377-381. https://doi.org/10.1038/ng1332.

Wilkinson, K.A., Nakamura, Y., and Henley, J.M. (2010). Targets and consequences of protein SUMOylation in neurons. Brain Res. Rev. 64, 195-212. https://doi. org/10.1016/j.brainresrev.2010.04.002.

Winborn, B.J., Travis, S.M., Todi, S.V., Scaglione, K.M., Xu, P., Williams, A.J., Cohen, R.E., Peng, J.M., and Paulson, H.L. (2008). The deubiquitinating enzyme ataxin-3, a polyglutamine disease protein, edits Lys(63) linkages in mixed linkage ubiquitin chains. J. Biol. Chem. 283, 26436-26443. https://doi.org/10.1074/jbc. M803692200.

Wohlschlegel, J.A., Johnson, E.S., Reed, S.I., and Yates, J.R. (2004). Global analysis of protein sumoylation in Saccharomyces cerevisiae. J. Biol. Chem. 279, 4566245668. https://doi.org/10.1074/jbc.M409203200.

Wójcik, C., Schroeter, D., Wilk, S., Lamprecht, J., and Paweletz, N. (1996). Ubiquitin-mediated proteolysis centers in HeLa cells: indication from studies of an inhibitor of the chymotrypsin-like activity of the proteasome. Eur. J. Cell Biol. 71, 311-318.

Wolin, S.L., and Cedervall, T. (2002). The La protein. Ann. Rev. Biochem. 71, 375-403. https://doi.org/10.1146/ annurev.biochem.71.090501.150003.

Xia, W. (2000). Role of presenilin in gamma-secretase cleavage of amyloid precursor protein. Exp. Gerontol. 35, 453-460.

Xiao, Y., Ma, B., McElheny, D., Parthasarathy, S., Long, F., Hoshi, M., Nussinov, R., and Ishii, Y. (2015). A $\beta$ (142) fibril structure illuminates self-recognition and replication of amyloid in Alzheimer's disease. Nat. Struct. Mol. Biol. 22, 499-505. https://doi.org/10.1038/ nsmb.2991.

Xu, H., He, X., Zheng, H., Huang, L.J., Hou, F., Yu, Z., de la Cruz, M.J., Borkowski, B., Zhang, X., Chen, Z.J., et al. (2014). Structural basis for the prion-like MAVS filaments in antiviral innate immunity. Elife 3, e01489. https://doi.org/10.7554/eLife.01489.

Xu, X.M. (2009). $\gamma$-Secretase catalyzes sequential cleavages of the A beta PP transmembrane domain. J. Alzheimers Dis. 16, 211-224. https://doi.org/10.3233/jad-20090957.

Yang, Z., Hong, J.Y., Derkatch, I.L., and Liebman, S.W. (2013). Heterologous gln/asn-rich proteins impede the propagation of yeast prions by altering chaperone availability. PLOS Genet. 9, e1003236. https://doi. org/10.1371/journal.pgen.1003236.

Yazawa, I., Nukina, N., Hashida, H., Goto, J., Yamada, M., and Kanazawa, I. (1995). Abnormal gene product identified in hereditary dentatorubral-pallidoluysian atrophy (DRPLA) brain. Nat. Genet. 10, 99-103. https://doi.org/10.1038/ng0595-99.

Ye, Y., and Rape, M. (2009). Building ubiquitin chains: E2 enzymes at work. Nat. Rev. Mol. Cell Biol. 10, 755-764. https://doi.org/10.1038/nrm2780.

Yedidia, Y., Horonchik, L., Tzaban, S., Yanai, A., and Taraboulos, A. (2001). Proteasomes and ubiquitin are involved in the turnover of the wild-type prion protein. EMBO J. 20, 5383-5391. https://doi.org/10.1093/ emboj/20.19.5383.

Yoo, S.Y., Pennesi, M.E., Weeber, E.J., Xu, B., Atkinson, R., Chen, S., Armstrong, D.L., Wu, S.M., Sweatt, J.D., and Zoghbi, H.Y. (2003). SCA7 knockin mice model human SCA7 and reveal gradual accumulation of mutant ataxin-7 in neurons and abnormalities in short-term plasticity. Neuron 37, 383-401.

Yoo, Y.S., Park, Y.Y., Kim, J.H., Cho, H., Kim, S.H., Lee, H.S., Kim, T.H., Sun Kim, Y., Lee, Y., Kim, C.J., et al. (2015). The mitochondrial ubiquitin ligase MARCH5 resolves MAVS aggregates during antiviral signalling. Nat. Commun. 6, 7910. https://doi.org/10.1038/ ncomms8910.

Yu, Y., Run, X., Liang, Z., Li, Y., Liu, F., Liu, Y., Iqbal, K., Grundke-Iqbal, I., and Gong, C.X. (2009). Developmental regulation of tau phosphorylation, tau kinases, and tau phosphatases. J. Neurochem. 108, 1480-1494. https://doi.org/10.1111/j.14714159.2009.05882.x.

Yuan, W.C., Lee, Y.R., Lin, S.Y., Chang, L.Y., Tan, Y.P., Hung, C.C., Kuo, J.C., Liu, C.H., Lin, M.Y., Xu, M., et al. (2014). K33-linked polyubiquitination of coronin 7 by Cul3-KLHL20 ubiquitin E3 ligase regulates protein trafficking. Mol. Cell 54, 586-600. https://doi. org/10.1016/j.molcel.2014.03.035.

Yun, S.M., Cho, S.J., Song, J.C., Song, S.Y., Jo, S.A., Jo, C., Yoon, K., Tanzi, R.E., Choi, E.J., and Koh, Y.H. (2013). SUMO1 modulates A $\beta$ generation via BACE1 accumulation. Neurobiol. Aging 34, 650-662. https:// doi.org/10.1016/j.neurobiolaging.2012.08.005.

Zannolli, R., Gilman, S., Rossi, S., Volpi, N., Bernini, A., Galluzzi, P., Galimberti, D., Pucci, L., D’Ambrosio, A., Morgese, G., et al. (2002). Hereditary neuronal intranuclear inclusion disease with autonomic failure 
and cerebellar degeneration. Arch. Neurol. 59, 13191326.

Zarranz, J.J., Alegre, J., Gómez-Esteban, J.C., Lezcano, E., Ros, R., Ampuero, I., Vidal, L., Hoenicka, J., Rodriguez, O., Atarés, B., et al. (2004). The new mutation, E46K, of alpha-synuclein causes Parkinson and Lewy body dementia. Ann. Neurol. 55, 164-173. https://doi. org/10.1002/ana.10795.

Zhang, Y.J., Xu, Y.F., Cook, C., Gendron, T.F., Roettges, P., Link, C.D., Lin, W.L., Tong, J., Castanedes-Casey, M., Ash, P., et al. (2009). Aberrant cleavage of TDP-43 enhances aggregation and cellular toxicity. Proc. Natl. Acad. Sci. U.S.A. 106, 7607-7612. https://doi. org/10.1073/pnas.0900688106.

Zhang, Y.Q. and Sarge, K.D. (2008). Sumoylation of amyloid precursor protein negatively regulates A beta aggregate levels. Biochem. Biophys. Res. Commun. 374, 673-678. https://doi.org/10.1016/j.bbrc.2008.07.109.

Zheng, Z., and Diamond, M.I. (2012). Huntington disease and the huntingtin protein. Prog. Mol. Biol. Transl. Sci. 107, 189-214. https://doi.org/10.1016/B978-0-12385883-2.00010-2.

Zhou, Y.F., Liao, S.S., Luo, Y.Y., Tang, J.G., Wang, J.L., Lei, L.F., Chi, J.W., Du, J., Jiang, H., Xia, K., et al. (2013). SUMO-1 modification on K166 of polyQ-expanded ataxin-3 strengthens its stability and increases its cytotoxicity. PLOS ONE 8, e54214. https://doi. org/10.1371/journal.pone.0054214.

Zoghbi, H.Y., and Orr, H.T. (2000). Glutamine repeats and neurodegeneration. Annu. Rev. Neurosci. 23, 217-247. https://doi.org/10.1146/annurev.neuro.23.1.217. 